Discussion Paper 124

Institute for Empirical Macroeconomics

Federal Reserve Bank of Minneapolis

90 Hennepin Avenue

Minneapolis, Minnesota 55480-0291

December 1997

\title{
A Markov Switching Model of GNP Growth With Duration Dependence*
}

Pok-sang Lam

Ohio State University

\begin{abstract}
We use a regime-switching model of real GNP growth to examine the duration dependence of business cycles. The model extends Hamilton (1989) and Durland and McCurdy (1994) and is estimated using both the postwar NIPA data and the secular data constructed by Balke-Gordon. We find that an expansion is more likely to end at a young age, that a contraction is more likely to end at an old age, that output growth slows over the course of an expansion, that a decline in output is mild at the beginning of a contraction, and that long expansions are followed by long contractions. This evidence taken together provides no support for the clustering of the whole-cycle around seven-to-ten year durations.
\end{abstract}

\footnotetext{
*This work was initiated while the author was a visiting scholar at the Institute For Empirical Macroeconomics, Federal Reserve Bank of Minneapolis, from July 2 to August 15, 1995. The author would like to thank the Institute for its hospitality and financial support. The paper has benefited from comments received from Stephen Cecchetti, G. S. Maddala, Nelson Mark, Huston McCulloch, Bruce Weinberg and the participants of a brown bag lunch at the Institute For Empirical Macroeconomics. The remaining shortcomings are solely those of the author. The views expressed herein are those of the author and not necessarily those of the Federal Reserve Bank of Minneapolis or the Federal Reserve System.
} 


\section{Introduction}

Whether the termination probability of an expansion or a contraction is an increasing function of its age, or whether business cycles exhibit positive duration dependence, is a question that has attracted the attention of a number of authors. The main strand of the literature examines the NBER reference cycle turning point dates. Huston McCulloch (1975) using a simple contingency table test, concludes that business cycles are duration independent. Employing a battery of non-parametric tests, Diebold and Rudebusch (1990) conclude that both duration independence in expansions and duration dependence in contractions are by and large consistent with the data. Sichel (1991), estimating a parametric hazard model using the NBER reference cycle turning points, finds statistically significant duration dependence in postwar contractions and prewar expansions.

A second strand of the literature find its basis in regime-switching time series models. In his pioneering work, James Hamilton (1989) estimates a two-state Markov chain model of output growth, where the two states are interpreted as expansions and contractions. His Markov chain assumes duration independence; as the current phase of the business cycle ages, the probability of moving into the alternative phase remains constant. Durland and McCurdy (1994) introduce duration dependence into the Hamilton model by allowing the transition probabilities to depend upon the age of the current phase of the cycle. They then infer duration dependence in postwar GNP growth rates using the estimated relationship between the transition probabilities and the age of the current phase. They find that as a contraction ages the probability of moving into an expansion increases and that this increase is statistically significant.

As the evidence is far from conclusive, there appears to be room for further investigation. Following Durland and McCurdy (1994), this paper empirically investigates duration dependence using a regime-switching model of GNP growth. We use a Hamilton (1989) model extended to contain a general structure for duration dependence. The model allows both the mean growth rates and the transition probabilities to depend upon the age of the current phase of the business cycle. This feature allows us to investigate the duration dependence associated with not only the 
phase-transition but also the amplitude of the cycle. The model also allows the transition probabilities to vary with the duration of the previous phase of the business cycle. This latter feature enables us to address those issues related to duration dependence raised by Diebold and Rudebusch (1990), Sichel (1991) and Diebold (1993). These include the effect of the duration of the current phase on the duration of the subsequent phase and peak-to-peak and trough-to-trough periodicity.

Instead of using the NBER reference cycle turning points as data, we treat the business cycle as an unobserved stochastic process and infer its duration dependence from GNP growth rate data. Our approach has a number of advantages. First, if the succession of expansions and contractions is driven by a stochastic process and the NBER identifies turning points with errors, those analyses based upon the NBER reference cycle chronology might not have desirable statistical properties. Our approach, however, yields reliable inference so long as our regimeswitching model captures the driving stochastic process. Second, methodologies that use the NBER reference cycle dates instead of growth rate data are better suited to forecasting turning points as opposed to forecasting growth rates over the course of the business cycle. Our methodology, in contrast, yields a stochastic process which can be used to forecast output growth rates. A comparison of the forecasting performance of our model with other prominent univariate time-series models would be of interest, but is beyond the scope of this paper. Our sole objective here is estimation.

We develop an algorithm to estimate the model via maximum likelihood, using growth rate data from postwar quarterly and from secular quarterly real GNP, with the latter of these being estimated by Balke and Gordon (1986). In both data series, we find evidence that, as an expansion ages, the growth rate of output declines. Surprisingly, the probability of reverting to a contraction does not increase, but decreases, with the age of the expansion. This is polar to the type of duration dependence motivating the literature ${ }^{1}$. In addition, we find evidence that the

\footnotetext{
${ }^{1}$ Burns (1968, p. 237) states, "experience strongly suggests that even in the absence of serious external disturbances the course of aggregate activity will in time be reversed by restrictive forces that gradually but insistently come into play as a result of the expansion process itself." McCulloch (1975) is explicitly motivated by this statement. Diebold and Rudebusch (1990) are motivated partly by the empirical work of Neftci (1982), who
} 
probability of a contraction ending increases as the contraction ages. Finally, in the secular data set, we find that the length of the current expansion has a positive effect on the duration of the subsequent contraction. Taken together, the duration dependence we have estimated provides no support for the clustering of the whole-cycle the seven-to-ten year durations often discussed in the literature (Diebold and Rudebusch 1990).

The remainder of this paper is organized as follows. Section 2 describes the statistical model and develops an algorithm to estimate it via maximum likelihood. Section 3 presents our empirical results. Finally, Section 4 offers some concluding remarks.

\section{The General Model and Estimation}

In this section, we present a univariate regime-switching model based upon Hamilton (1989) and Durland and McCurdy (1994). Our model differs from both by incorporating mean growth rates that are dependent upon the duration of the current phase and transition probabilities that are dependent upon the durations of both the current and the previous phases.

The section is divided into four subsections. In Section 2.1, we describe the general model. The algorithm used to estimate this model via maximum likelihood is developed in Section 2.2. Issues concerning smoothing are discussed in Section 2.3. The parameterizations needed to implement the estimation are discussed in Section 2.4.

Throughout this section, $y$ is the growth rate of the observed time series, $Y$ is the current value and the past history of $y, S$ is the Markov state variable, and $D$ is the age of the current

assumes that the longer the economy remains in one state, the more likely it is to make a transition to the other. They also allude to the hypothesis often seen in the public press, that "a very long expansion is unstable and is unusually likely to end." Sichel (1991) begins with the question, "Are periods of expansion or contraction in economic activity more likely to end as they become older?" 
state. $D L$ denotes the duration of the last run of states, and $\theta$ is the set of estimable parameters in the model.

\subsection{The General Model}

The growth rate of output is comprised of two unobserved components, a linear component denoted by $\mathrm{z}$ and a nonlinear component denoted $\mu$. With the latter of these being a deterministic function of $S$ and $D$, the model is written as follows:

$$
y_{t}=\mu\left(S_{t}, D_{t}\right)+z_{t}
$$

The linear component follows a k-th order stationary autoregressive process,

$$
\phi(L) z_{t}=\varepsilon_{t},
$$

where $\varepsilon_{t} \sim$ i.i.d. $\mathrm{N}\left(0, \sigma^{2}\right)$ and $\phi(L)=1-\phi 1 L-\phi 2 L^{2}-\ldots-\phi k L^{k}$.

The dynamics of the nonlinear component are driven by the following two-point Markov chain, which is independent of the autoregressive process:

$$
S_{t} \in\{0,1\},
$$

where

$$
\begin{aligned}
& \operatorname{Pr}\left[S_{t+1}=0 / S_{t}=0, D_{t}, D L_{t}\right]=\pi 0\left(D_{t}, D L_{t}\right) \\
& \operatorname{Pr}\left[S_{t+1}=1 / S_{t}=0, D_{t}, D L_{t}\right]=1-\pi 0\left(D_{t}, D L_{t}\right) \\
& \operatorname{Pr}\left[S_{t+1}=1 / S_{t}=1, D_{t}, D L_{t}\right]=\pi 1\left(D_{t}, D L_{t}\right) \\
& \operatorname{Pr}\left[S_{t+1}=0 / S_{t}=1, D_{t}, D L_{t}\right]=1-\pi 1\left(D_{t}, D L_{t}\right) .
\end{aligned}
$$


Equation (3) gives the transition probabilities of the Markov chain, which are between zero and one. We refer to $\mu$ as the mean growth rate, as it is the value that the time series takes when the linear component is equal to its unconditional mean, or zero. With a suitable normalization, $\mu$ can be chosen such that it is generally larger when $S=0$ than when $S=1$. In this case, $S=0$ is interpreted as an expansion while $S=1$ is interpreted as a contraction.

Our model allows for two types of duration dependence. The first is the dependence of the dynamics of the nonlinear component on the age of the current phase. This can be seen in equations (1) and (3), where the mean growth rate and the probability of exiting the current state, respectively, depend upon the age of the current phase. The second is the dependence of the nonlinear component on the duration of the previous phase of the cycle. This is also evident in equation (3), where the probability of exiting the current state depends upon the duration of the previous phase of the cycle.

When neither the mean growth rate nor the transition probabilities depend upon the two duration variables, the model reduces to the standard Hamilton model. When the mean growth rate does not depend upon the duration variables and the transition probabilities depend only upon the duration of the current phase, we have the duration-dependent model estimated in Durland and McCurdy (1994). Since the Hamilton model and Durland and McCurdy's model are nested within our general model, with a suitable parameterization of the mean growth rates and the transition probabilities, both models can in principle be tested.

We restrict the Markov chain to have a memory of $d m$ periods. More specifically, in equations (1) and (3), we assume that durations beyond $d m$ have no marginal effect on the mean growth rates and the transition probabilities of the Markov chain. This assumption is motivated by the convenience in estimation. It implies that durations exceeding $d m$ are observationally equivalent to, and can be treated the same as, a duration of $d m$ in the evaluation of the likelihood function. 
We now consider the maximum likelihood estimation of the model. Maximum likelihood estimation of a regime switching model is conceptually straightforward, but the evaluation of the log-likelihood function is nonstandard. In the next subsection, we devise an algorithm which evaluates the log-likelihood of the sample as a function of the vector $\theta$, consisting of $\phi 1, \phi 2, \ldots$, $\phi \mathrm{k}, \sigma$ and the parameters characterizing the dependence of $\mu, \pi 0$ and $\pi 1$ on $S, D$ and $D L$. The algorithm is tedious; readers uninterested in the technical details may proceed directly to Section 2.3, where we discuss the inference on $\mathrm{S}$, the unobserved state, given the available information.

\subsection{The Algorithm}

To begin, consider the prediction error decomposition of the log-likelihood function. According to this decomposition, the log-likelihood of the sample can be computed by summing the conditional log-likelihoods. Each conditional log-likelihood is the log-likelihood of an observation, conditional upon its past history. If the conditional log-likelihoods depend upon a small set of variables and if these variables, conditional upon the past history of the observations, are Markovian, then Bayes theorem can be used to evaluate them recursively. This is the insight originally exploited by Hamilton (1989). Following this insight, we search for a set of state variables which are (1) Markovian and (2) sufficient for evaluating the conditional likelihoods.

To find the set of state variables satisfying these criteria, we multiply both sides of (1) by the polynomial $\phi(L)$ and use (2) to obtain

$$
\varepsilon_{t}=y_{t}-\sum_{i=1}^{k} \phi i y_{t-i}-\mu\left(S_{t}, D_{t}\right)+\sum_{i=1}^{k} \phi i \mu\left(S_{t-i}, D_{t-i}\right) .
$$

Equation (4) shows that the joint probability distribution of $\left\{S_{i}\right\}_{i=t-k}^{t}$ and $\left\{D_{i}\right\}_{i=t-k}^{t}$, is sufficient for evaluating the conditional likelihood of an observation at time $t$. It follows, trivially, that the joint distribution of $\left\{S_{i}\right\}_{i=t-k}^{t},\left\{D_{i}\right\}_{i=t-k}^{t}$ and $\left\{D L_{i}\right\}_{i=t-k}^{t}$ is sufficient as well. In addition, if the probability distribution of $\left\{S_{i}\right\}_{i=t-k}^{t},\left\{D_{i}\right\}_{i=t-k}^{t}$ and $\left\{D L_{i}\right\}_{i=t-k}^{t}$ is known, the probability distribution of $\left\{S_{i}\right\}_{i=t-k+1}^{t+1},\left\{D_{i}\right\}_{i=t-k+1}^{t+1}$ and $\left\{D L_{i}\right\}_{i=t-k+1}^{t+1}$, can be derived using the 
transition probabilities equation (3). Thus, the set of variables, $\left\{S_{i}\right\}_{i=t-k}^{t},\left\{D_{i}\right\}_{i=t-k}^{t}$ and $\left\{D L_{i}\right\}_{i=t-k}^{t}$ are Markovian. Therefore, $\left\{S_{i}\right\}_{i=t-k}^{t},\left\{D_{i}\right\}_{i=t-k}^{t}$ and $\left\{D L_{i}\right\}_{i=t-k}^{t}$ can be used as state variables in the recursive evaluation of the likelihood function.

Simplification is possible, however. If we know $\left\{S_{i}\right\}_{i=t-k}^{t}, D_{t-k}$ and $D L_{t-k}$, it is possible to recover $\left\{S_{i}\right\}_{i=t-k}^{t},\left\{D_{i}\right\}_{i=t-k}^{t}$ and $\left\{D L_{i}\right\}_{i=t-k}^{t}$. It follows that the set of state variables, $\left\{S_{i}\right\}_{i=t-k}^{t}, \quad D_{t-k}$ and $D L_{t-k}$, is sufficient to evaluate the conditional likelihood of the observation at time t. In addition, using the transition probabilities in (3), the probability distribution of $\left\{S_{i}\right\}_{i=t-k+1}^{t+1}, \quad D_{t-k+1}$ and $D L_{t-k+1}$ can be computed from the probability distribution of $\left\{S_{i}\right\}_{i=t-k}^{t}, D_{t-k}$ and $D L_{t-k}$. Thus, this smaller set of state variables is Markovian. Therefore, we can evaluate the likelihood function recursively, using $\left\{S_{i}\right\}_{i=t-k}^{t}, D_{t-k}$ and $D L_{t-k}$ as the state variables.

This method is an extension of Hamilton (1989) and Durland and McCurdy (1994) to the case where both the transition probabilities and the mean growth rate depend upon the age of the current phase and the duration of the previous phase. If neither type of duration dependence is present, then $\left\{S_{i}\right\}_{i=t-k}^{t}$ is sufficient to evaluate the conditional likelihoods. This is the case presented in Hamilton (1989). If the duration of the last phase does not affect the transition probabilities and the mean growth rates are constant, the set of state variables required for evaluating the conditional likelihoods is $\left\{S_{i}\right\}_{i=t-k}^{t}$ and $D_{t}$. This is the case presented in Durland and McCurdy (1994).

When both the transition probabilities and the mean growth rates depend upon the age of the current phase, but not the duration of the previous phase, it is interesting to note that the set of state variables used to evaluate the conditional likelihood at time $\mathrm{t}$ is $\left\{S_{i}\right\}_{i=t-k}^{t}$ and $D_{t-k}$. This is not equivalent to the set of state variables employed by Durland and McCurdy (1994). When the mean growth rates depend upon the age of the current phase, to evaluate the conditional 
likelihood at time t, it is necessary to know $\left\{D_{i}\right\}_{i=t-k}^{t}$. While it is possible to recover these values from $\left\{S_{i}\right\}_{i=t-k}^{t}$ and $D_{t-k}$, it is impossible to do so from $\left\{S_{i}\right\}_{i=t-k}^{t}$ and $D_{t}$.

Below we describe an algorithm for evaluating the likelihood function, using as the state variables $\left\{S_{i}\right\}_{i=t-k}^{t}, D_{t-k}$ and $D L_{t-k}$. The algorithm is summarized in the following five steps:

Step 1: For $s_{0}=0,1, s_{1}=0,1, s_{2}=0,1, \ldots, s_{k-1}=0,1, s_{k}=0,1, d 1=1,2, \ldots, d m, d 2=1,2, \ldots$, $d m$, and starting with $\delta_{0}=d 1, \delta \delta_{0}=d 2$, calculate

$\delta_{i}=\delta_{i-1}\left(1-\left|s_{k-i}-s_{k-i+1}\right|\right)+1$ and

$\delta \delta_{i}=\delta \delta_{i-1}\left(1-\left|s_{k-i}-s_{k-i+1}\right|\right)+\delta_{i-1}\left|s_{k-i}-s_{k-i+1}\right|$,

for $\mathrm{i}=1,2, \ldots, \mathrm{k}-1, \mathrm{k}$. Set $\delta_{i}$ equal to $d m$ whenever it exceeds $d m$. Store these two sequences as

$\gamma 1\left(s_{0}, s_{1}, s_{2}, \ldots, s_{k}, d 1, d 2, i\right)=\delta_{i}$ and

$\gamma 2\left(s_{0}, s_{1}, s_{2}, \ldots, s_{k}, d 1, d 2, i\right)=\delta \delta_{i}, \mathrm{i}=0,1,2, \ldots, \mathrm{k}-1, \mathrm{k}$.

Step 2: For $s_{0}=0,1, s_{1}=0,1, s_{2}=0,1, \ldots ., s_{k-1}=0,1, s_{k}=0,1, d 1=1,2, \ldots . d m, d 2=$ $1,2, \ldots ., d m$, then compute

$$
\begin{gathered}
\operatorname{Pr}\left[S_{t}=s_{0}, S_{t-1}=s_{1}, \ldots, S_{t-k}=s_{k}, D_{t-k}=d 1, D L_{t-k}=d 2 / Y_{t-1}, \theta\right] \\
=\sum_{d 3=1}^{d m} \operatorname{Pr}\left[S_{t-1}=s_{1}, \ldots, S_{t-k}=s_{k}, S_{t-k-1}=s, D_{t-k-1}=d 2, D L_{t-k-1}=d 3 / Y_{t-1}, \theta\right] \\
\operatorname{Pr}\left[S_{t}=s_{0} / S_{t-1}=s_{1}, D_{t-1}=\gamma 1\left(s_{1}, s_{2}, \ldots, s_{k}, s, d 2, d 3, k\right),\right. \\
\left.D L_{t-1}=\gamma 2\left(s_{1}, s_{2}, \ldots, s_{k}, s, d 2, d 3, k\right)\right]
\end{gathered}
$$

when $d 1=1$, where $\mathrm{s}=1-s_{k}$;

$$
\begin{aligned}
& \operatorname{Pr}\left[S_{t}=s_{0}, S_{t-1}=s_{1}, \ldots, S_{t-k}=s_{k}, D_{t-k}=d 1, D L_{t-k}=d 2 / Y_{t-1}, \theta\right] \\
& =\operatorname{Pr}\left[S_{t-1}=s_{1}, \ldots, S_{t-k}=s_{k}, S_{t-k-1}=s_{k}, D_{t-k-1}=d 1-1, D L_{t-k-1}=d 2 / Y_{t-1}, \theta\right] \\
& \quad \operatorname{Pr}\left[S_{t}=s_{0} / S_{t-1}=s_{1}, D_{t-1}=\gamma 1\left(s_{1}, s_{2}, \ldots, s_{k}, s_{k}, d 1-1, d 2, k\right),\right.
\end{aligned}
$$




$$
\left.D L_{t-1}=\gamma 2\left(s_{1}, s_{2}, \ldots, s_{k}, s_{k}, d 1-1, d 2, k\right)\right]
$$

when $1<d 1<d m$; and

$$
\begin{gathered}
\operatorname{Pr}\left[S_{t}=s_{0}, S_{t-1}=s_{1}, \ldots, S_{t-k}=s_{k}, D_{t-k}=d 1, D L_{t-k}=d 2 / Y_{t-1}, \theta\right] \\
=\sum_{j=0}^{1} \operatorname{Pr}\left[S_{t-1}=s_{1}, \ldots, S_{t-k}=s_{k}, S_{t-k-1}=s_{k}, D_{t-k-1}=d m-j, D L_{t-k-1}=d 2 / Y_{t-1}, \theta\right] \\
\operatorname{Pr}\left[S_{t}=s_{0} / S_{t-1}=s_{1}, D_{t-1}=\gamma 1\left(s_{1}, s_{2}, \ldots, s_{k}, s_{k}, d m-j, d 2, k\right),\right. \\
\left.D L_{t-1}=\gamma 2\left(s_{1}, s_{2}, \ldots, s_{k}, s_{k}, d m-j, d 2, k\right)\right]
\end{gathered}
$$

when $d 1=d m$.

Step 3: Calculate, for $s_{0}=0,1, s_{1}=0,1, s_{2}=0,1, \ldots, s_{k-1}=0,1, s_{k}=0,1, d 1=1,2, \ldots$. $d m, d 2=1,2, \ldots, d m$,

$$
\begin{aligned}
& \operatorname{Pr}\left[y_{t}, S_{t}=s_{0}, S_{t-1}=s_{1}, \ldots, S_{t-k}=s_{k}, D_{t-k}=d 1, D L_{t-k}=d 2 / Y_{t-1}, \theta\right] \\
& =\operatorname{Pr}\left[S_{t}=s_{0}, S_{t-1}=s_{1}, \ldots, S_{t-k}=s_{k}, D_{t-k}=d 1, D L_{t-k}=d 2 / Y_{t-1}, \theta\right] \\
& \frac{1}{\sqrt{2 \pi} \sigma} \exp \left\{-\frac{1}{2 \sigma^{2}}\left[y_{t}-\mu\left(s_{0}, \gamma 1\left(s_{0}, s_{1}, \ldots, s_{k}, d 1, d 2, k\right)\right)\right.\right. \\
& \left.\left.-\sum_{j=1}^{k} \phi j\left(y_{t-j}-\mu\left(s_{j}, \gamma 1\left(s_{0}, s_{1}, \ldots, s_{k}, d 1, d 2, k-j\right)\right)\right)\right]^{2}\right\}
\end{aligned}
$$

Step 4: From this, then compute

$\operatorname{Pr}\left[y_{t} / Y_{t-1}, \theta\right]=\sum_{s_{0}=0}^{1} \sum_{s_{1}=0}^{1} \cdots \sum_{s_{k}=0}^{1} \sum_{d 1=1}^{d m} \sum_{d 2=1}^{d m}$

$\operatorname{Pr}\left[y_{t}, S_{t}=s_{0}, S_{t-1}=s_{1}, \ldots, S_{t-k}=s_{k}, D_{t-k}=d 1, D L_{t-k}=d 2 / Y_{t-1}, \theta\right]$

Step 5: Finally, calculate, for $s_{0}=0,1, s_{1}=0,1, s_{2}=0,1, \ldots, s_{k-1}=0,1, s_{k}=0,1, d 1=1$,

$2, . . ., d m, d 2=1,2, \ldots . d m$,

$$
\begin{aligned}
& \operatorname{Pr}\left[S_{t}=s_{0}, S_{t-1}=s_{1}, \ldots, S_{t-k}=s_{k}, D_{t-k}=d 1, D L_{t-k}=d 2 / Y_{t}, \theta\right] \\
& =\frac{\operatorname{Pr}\left[y_{t}, S_{t}=s_{0}, S_{t-1}=s_{1}, \ldots, S_{t-k}=s_{k}, D_{t-k}=d 1, D L_{t-k}=d 2 / Y_{t-1}, \theta\right]}{\operatorname{Pr}\left[y_{t} / Y_{t-1}, \theta\right]}
\end{aligned}
$$


Step 1 produces inputs for Steps 2 and 3. Step 2 uses as inputs the outputs of Steps 1 and 5 from the previous observation and produces output for Step 3. Step 3 produces output for use in Step 4. In moving through these five steps, the algorithm produces the conditional likelihood of an observation (the output of Step 4) and the filtered probability distribution of the state variables (the output of Step 5). The steps are repeated for the next observation until the end of the sample is reached. Since Step 1 is identical for all observations, after the first observation the algorithm can begin with Step 2.

The log-likelihood function is the sum of the logs of the conditional likelihoods of the observations, or

$$
L\left(y_{T}, y_{T-1}, y_{T-2}, \ldots, y_{2}, y_{1} ; \theta\right)=\sum_{t=1}^{T} \log \left(\operatorname{Pr}\left[y_{t} / Y_{t-1}, \theta\right]\right)
$$

To initialize the algorithm, the probability distribution of the states is needed in Step 2. This is provided by the unconditional distribution of the states implied by the transition probabilities, which we obtain numerically by iterating on the probabilities stacked into a matrix.

We note that this algorithm is computationally quite burdensome, particularly when the duration of the previous phase is permitted to affect the duration of the current phase. Faster but potentially less accurate techniques of approximating the log-likelihood function can be implemented along the lines of Kim (1994). Kim has demonstrated that his approximate maximum likelihood is very close to the exact maximum likelihood in estimating the model in Lam (1990), which is the Hamilton model with a stationary linear process.

\subsection{Smoothing}

A by-product of our algorithm is an inference about the unobserved Markov state based on currently available information, or 


$$
\begin{aligned}
& \operatorname{Pr}\left[S_{t}=s_{0} / Y_{t}, \theta\right]=\sum_{d 1=1}^{d m} \sum_{d 2=1}^{d m} \sum_{s_{1}=0}^{1} \cdots \sum_{s_{k}=0}^{1} \\
& \operatorname{Pr}\left[S_{t}=s_{0}, S_{t-1}=s_{1}, \ldots, S_{t-k}=s_{k}, D_{t-k}=d 1, D L_{t-k}=d 2 / Y_{t}, \theta\right]
\end{aligned}
$$

The probabilities on the right-hand side are the outputs of Step 5 of the algorithm in Section 2.2, evaluated at the maximum likelihood estimate of $\theta$. This same set of probabilities can be used to obtain more reliable inferences on the lagged values of the state, using currently available information. For example, one can calculate a k-lag smoother as

$$
\begin{aligned}
& \operatorname{Pr}\left[S_{t-k}=s_{k} / Y_{t}, \theta\right]=\sum_{d 1=1}^{d m} \sum_{d 2=1}^{d m} \sum_{s_{0}=0}^{1} \cdots \sum_{s_{k-1}=0}^{1} \\
& \operatorname{Pr}\left[S_{t}=s_{0}, S_{t-1}=s_{1}, \ldots . ., S_{t-k}=s_{k}, D_{t-k}=d 1, D L_{t-k}=d 2 / Y_{t}, \theta\right] .
\end{aligned}
$$

An important use of the k-lag smoother is dating business cycle turning points. In empirical work, the smoothed probability of being in a low-growth state is often used as a criterion for determining whether a given period is characterized as expansionary or contractionary. In practice, the NBER may not recognize periods of brief declines in output as contractions. In the context of our model, this practice is similar to recognizing a state only if the duration in that state exceeds, or will eventually exceed, $\lambda$ periods. Dating business cycle turning points while imposing such a 'maturity criterion' can be performed using a modified version of the $\mathrm{k}$-lag smoother in equation (7). Specifically, assuming $\mathrm{k}$ is greater than $\lambda$, the probability of period $\mathrm{t}-\mathrm{k}$ being in state $\mathrm{s}$, taking into account the maturity criterion, can be computed as

$$
\begin{aligned}
& \operatorname{Pr}\left[S_{t-k}=s / Y_{t}, \theta\right]=\sum_{\omega=1}^{\lambda} \sum_{d 2=1}^{d m} \sum_{s_{0}=0}^{1} \sum_{s_{1}=0}^{1} \ldots \sum_{s_{k-\lambda+\omega-2}=0}^{1} \operatorname{Pr}\left[S_{t}=s_{0}, S_{t-1}=s_{1}, \ldots\right. \\
& \left.S_{t-k+\lambda-\omega+2}=s_{k-\lambda+\omega-2}, S_{t-k+\lambda-\omega+1}=s, \ldots, S_{t-k}=s, D_{t-k}=\omega, D L_{t-k}=d 2 / Y_{t}, \theta\right] \\
& +\sum_{d 1=\lambda+1}^{d m} \sum_{d 2=1}^{d m} \sum_{s_{0}=0}^{1} \sum_{s_{1}=0}^{1} \ldots \sum_{s_{k-1}=0}^{1} \operatorname{Pr}\left[S_{t}=s_{0}, S_{t-1}=s_{1}, \ldots,\right.
\end{aligned}
$$




$$
\left.S_{t-k+1}=s_{k-1}, S_{t-k}=s, D_{t-k}=d 1, D L_{t-k}=d 2 / Y_{t}, \theta\right] .
$$

\subsection{Parameterization}

Estimation requires parameterizations for the mean growth rates and the transition probabilities. Following Durland and McCurdy (1994), we assume that the transition probabilities are logistic functions of the two duration variables. Furthermore, we assume that the relationship between the mean growth rate and the age of current phase is quadratic. In summary, we have

$$
\mu\left(S_{t}, D_{t}\right)=\alpha 0\left(S_{t}\right)+\alpha 1\left(S_{t}\right)\left(D D_{t}-1\right)+\alpha 2\left(S_{t}\right)\left(D D_{t}-1\right)^{2},
$$

where $S_{t}=0,1$, and

$$
\begin{gathered}
\pi 0\left(D_{t}, D L_{t}\right)=\frac{\exp \left[\beta 0(0)+\beta 1(0)\left(D D_{t}-1\right)+\beta 2(0)\left(D D L_{t}-1\right)\right]}{1+\exp \left[\beta 0(0)+\beta 1(0)\left(D D_{t}-1\right)+\beta 2(0)\left(D D L_{t}-1\right)\right]}, \\
\pi 1\left(D_{t}, D L_{t}\right)=\frac{\exp \left[\beta 0(1)+\beta 1(1)\left(D D_{t}-1\right)+\beta 2(1)\left(D D L_{t}-1\right)\right]}{1+\exp \left[\beta 0(1)+\beta 1(1)\left(D D_{t}-1\right)+\beta 2(1)\left(D D L_{t}-1\right)\right]},
\end{gathered}
$$

where $D D_{t}=\operatorname{Min}\left(D_{t}, d m\right)$ and $D D L_{t}=\operatorname{Min}\left(D L_{t}, d m\right)$.

The pair of quadratic functions in (9a), encompasses a rich set of dynamics over the course of the business cycle, including the growth rate first increasing and then decreasing, and first decreasing and then increasing, over a given phase. For example, if $\alpha 1(0)$ is positive and $\alpha 2(0)$ is negative, the growth rate increases during the early stages of and subsequently decreases over the later part of an expansion. A special case of the quadratic function is a linear relationship, which can be obtained by setting the quadratic coefficient to zero. A linear relationship has the advantage of parsimony in parameter but is more restrictive, implying that the mean growth rates 
are monotonic in the age of the phase. This monotonicity rules out the possibility that output declines are most severe in the middle of a contraction and that the output growth is most rapid in the middle of an expansion.

In (9b) and (9c), the coefficients $\beta 1(0)$ and $\beta 1(1)$ determine the relationship between the probability of exiting the current state and the age of the current phase. When $\beta 1(0)$ is negative, the probability of remaining in an expansion is decreasing in, or the probability of leaving an expansion is positively related to, the age of the current expansion. In this case, the expansion is said to exhibit positive duration dependence. Likewise, if $\beta 1(1)$ is negative, the contraction is said to exhibit positive duration dependence. The coefficients $\beta 2(0)$ and $\beta 2(1)$ determine the relationship between the probability of exiting the current state and the duration of the previous phase. When $\beta 2(0)$ is negative (positive), the probability of an expansion terminating is increasing (decreasing) in the length of the last contraction. When $\beta 2(1)$ is negative (positive), the probability of a contraction terminating is increasing (decreasing) in the length of the last expansion. Table 1 summarizes the model and its parameters.

\section{Empirical Results}

Using the algorithm described in Section 2.2, the model is estimated using maximum likelihood. The log-likelihood function is calculated as a function of the parameters comprising the mean growth rates $(\alpha 0(0), \alpha 1(0), \alpha 2(0), \alpha 0(1), \alpha 1(1), \alpha 2(1))$, the transition probabilities $(\beta 0(0)$, $\beta 1(0), \beta 2(0), \beta 0(1), \beta 1(1), \beta 2(1))$, and the autoregressive process $(\sigma, \phi 1, \phi 2, \ldots .$. , and $\phi \mathrm{k})$.

The maximization of this function with respect to these parameters is carried out using, sequentially, the Nelder-Mead Simplex, the Davidson-Fletcher-Powell, and the Quadratic HillClimbing algorithms. The covariance matrix of the estimates is computed numerically from the negative inverse of the Hessian of the log-likelihood function, evaluated at these estimates. The number of lags in the autoregressive process, $\mathrm{k}$, and the maximum memory of the Markov chain, $d m$, are determined prior to estimation. We follow both Hamilton (1989) and Durland and 
McCurdy (1994) in setting $\mathrm{k}$ equal to four ${ }^{2}$. We set $d m$ equal to forty quarters, which seems reasonable as one would normally expect an expansion or a contraction to last for no more than forty quarters.

The model is estimated to two data series. The first is the growth rate of postwar quarterly real GNP, extending from 1952:2 to 1996:4. This data, derived from the standard NIPA series available in the Survey of Current Business, is an updated and revised version of that data used in Hamilton (1989) and Durland and McCurdy (1994) ${ }^{3}$. The second series is the growth rate of secular quarterly real GNP, extending from 1875:1 to 1946:4. This data is derived from a real GNP series estimated by Balke and Gordon (1986). The advantage of their data is its long time span, which is an important factor in estimating the effect of the duration of the previous phase on the duration of the current phase. Also, the use of secular data may shed light on the characteristics of the business cycle both before and after WW2. An important caveat is that the Balke-Gordon data was not collected quarterly. Rather, the series is the result of a careful interpolation of annual real GNP to a quarterly index of production and trade. To the extent that production and trade sectors are more volatile than other sectors of the economy, this series most likely exaggerates the amplitude of output fluctuations ${ }^{4}$.

Considering only the postwar data, we first ignore the effect of the duration of the previous phase on the current phase. These results are presented in Section 3.1. The ability of these models to match the postwar NBER reference cycle turning points is discussed in Section 3.2. We then consider the Balke-Gordon data, again ignoring the effect of the duration of the

\footnotetext{
${ }^{2}$ Lam (1990) considers an autoregressive process with two and three lags in levels, which is roughly equivalent to $\mathrm{k}$ equal to one or two; his results are not sensitive to the choice of $\mathrm{k}$.

${ }^{3}$ Real GNP from the NIPA is available beginning in 1947:1. We follow the literature in starting the sample in 1952:2, thereby avoiding the observations surrounding the Korean War. None of the paper's major conclusions are sensitive to this choice of sample period. The data series is reported in Table 2A, Survey of Current Business, May 1995.

${ }^{4}$ Potter (1995) uses the same data series to estimate the impulses during the Great Depression. Specifically, he fits a linear model and a nonlinear Self-Exciting Threshold Autogression (SETAR) to the series and treats the estimated residuals as impulses. The impulses estimated for the Depression-era are then fed into the models estimated using post-1945 data in order to determine if the postwar propagation mechanism reproduces the Great Depression.
} 
previous phase on the duration of the current phase. These results are presented in Section 3.3. In Section 3.4, we present results for the case where the duration of the current phase depends upon the duration of the previous phase.

\subsection{Postwar Data}

We begin by presenting the benchmark case, the Hamilton (1989) model with no duration dependence. Here, the duration dependence parameters associated with the transition probabilities $(\beta 1(0), \beta 2(0), \beta 1(1), \beta 2(1))$, and the duration dependence parameters associated with the mean growth rates $(\alpha 1(0), \alpha 2(0), \alpha 1(1), \alpha 2(1))$ all equal zero. The results, presented in Table 2 , are qualitatively similar to those presented in Hamilton (1989). Quantitatively, however, there are important differences. First, the probability of remaining in a contraction, evaluated using equation (9c), is 0.21; this probability in Hamilton (1989) is 0.76. In addition, the mean growth rates of expansions and contractions are estimated to be 0.85 and -1.50 percent, respectively; in Hamilton (1989), they are 1.18 and -0.36 percent, respectively. Therefore, in comparison to Hamilton (1989), our estimates imply not only that expansions are milder but also that contractions are shorter and more severe.

Hamilton's (1989) estimates are based upon a sample extending from 1952:2 to 1984:4. The differences between our results and his, however, do not stem from the addition of 48 quarters to the data. When the model is estimated using our series over his shorter sample period, the probability of remaining in a contraction is 0.20 . The differences are, therefore, completely due to a revision of the data series by the BEA. BEA has recently moved from a fixed-weighted basis to a chain-weighted basis in compiling real GNP. This change improves accuracy when evaluating the strength of expansions and the depth of contractions by minimizing the problem of substitution bias. The net effect to the real GNP series is to raise the magnitude of both output growth in expansions and output declines in contractions ${ }^{5}$. The larger declines in contractions

\footnotetext{
${ }^{5}$ See the discussion in the Survey of Current Business, July 1995.
} 
force our estimate of the mean contraction growth rate to be large and negative. Because declines of such magnitude are rare in the postwar data, our estimates of the benchmark Hamilton model imply that contractions are short-lived and infrequent.

We now examine the case where the mean growth rate in a period depends upon the duration of the current phase of the cycle. The transition probabilities are assumed to be constant, as in the benchmark Hamilton model. That is, we set $\beta 1(0), \beta 2(0), \beta 1(1)$ and $\beta 2(1)$ equal to zero. Table 3 reports our estimates from four alternative versions of this model. Column 1 reports estimates of a model for which the mean growth rates of the expansionary state depends linearly upon the age of the expansion. Column 2 reports estimates of a model for which the mean growth rates of the contractionary state depend linearly upon the age of the contraction. Column 3 reports estimates of a model for which the mean growth rates of both expansions and contractions depend linearly upon the age of the current phase. Finally, column 4 report estimates of a model for which the mean growth rates of both expansions and contractions depend quadratically upon the age of the current phase.

Judging from the asymptotic t-ratios, the effect of the duration of the current phase on the mean growth rates is quadratic for both expansions and contractions. We therefore focus on the parameter values reported in column 4. Because $\alpha 1(0)$ is negative and $\alpha 2(0)$ is positive, the mean growth rates first decline as the expansion ages, with this decline gradually leveling off. As $\alpha 2(0)$ is small, the growth rate of output never regains much ground after reaching its minimum at about eight years. When an expansion begins, output grows at 1.567 percent per quarter, but after eight years the growth rate is only 0.472 percent, which differs only mildly from the onset of a contraction. The estimates of $\alpha 1(1)$ and $\alpha 2(1), 1.423$ and -0.657 , respectively, imply a rich set of dynamics for output growth during a contraction. When a contraction begins, output declines at a rate of 0.812 percent per quarter. This decline in output is halted temporarily in the second quarter of a contraction. After the second quarter, however, if the contraction continues, output declines again, reaching a rate of 2.031 percent in four quarters. It is worth noting that now the probability of remaining in a contraction is 0.564 , close to that estimated in Hamilton (1989). 
The mean output growth rates implied by our estimates are sharply different from those associated with the benchmark Hamilton model and with the Durland and McCurdy (1994)'s duration-dependent model. The latter two models assume that the mean growth rate of output is constant over each phase of the business cycle. As the benchmark Hamilton model is nested within the models estimated in Table 3, it can be tested using either the likelihood ratio test or the asymptotic Wald-test. On the basis of either, we can reject, at the 1 percent significance level, the Hamilton model in favor of a model with either quadratically or linearly duration-dependent mean growth rates. Overall, Table 3 provides strong evidence that the mean growth rate of output is not constant over either phase of the business cycle.

We now turn to the duration dependence in transition probabilities examined by Durland and McCurdy (1994). Table 4 reports estimates of three versions of the model for which the transition probabilities depend upon the age of the current phase. Column 1 reports estimates of a model with duration-dependent transition probabilities and constant mean growth rates. This is the case examined by Durland and McCurdy (1994). Column 2 reports estimates of a model where the mean growth rates depend linearly upon the age of the current phase and where the transition probabilities are duration-dependent. This is the model in column 3 of Table 3 , augmented by unrestricted $\beta 1(0)$ and $\beta 1(1)$. Finally, in column 3, we report estimates of a model for which the mean growth rates depend quadratically upon the age of the current phase and for which the transition probabilities are duration-dependent. This is the model in column 4 of Table 3 , once again augmented by unrestricted $\beta 1(0)$ and $\beta 1(1)$.

Column 1 shows that, given a constant mean growth rate over each phase of the cycle, duration dependence in the transition probabilities is not statistically significant at the 10 percent level using either the likelihood ratio test or the asymptotic Wald-test. These are essentially the same tests conducted by Durland and McCurdy (1994) for the null of no duration dependence in the transition probabilities. They reject the null of no dependence in the transition probabilities of a contraction, but not the null of no dependence in the transition probabilities of an expansion. Our results show that with longer, revised data series the conclusions reached by Durland and McCurdy (1994) are no longer warranted. Based on the estimates presented in column 1, we 
would conclude that duration dependence is absent in both postwar expansions and postwar contractions. This result is suggested by Table 2. Given that the benchmark Hamilton model implies that the expected duration of a contraction is only approximately one quarter, there is little room for duration-dependent transition probabilities to improve the fit of the model.

Column 2 shows that, once we have introduced duration dependence into the mean growth rates of the phases, the duration dependence in the transition probabilities is statistically significant. The likelihood ratio test for the model in column 2 versus the benchmark Hamilton model in Table 2 is 13.618, implying that the null of the benchmark Hamilton model is rejected at the 1 percent level. The probability of remaining in a contraction now exhibits a clear tendency to decrease as the contraction ages. At the onset of a contraction, this probability is 0.664 , but after one quarter it falls to 0.226 , becoming negligible after only two quarters. Most of the statistical significance of the duration dependence appears, however, to be associated with expansions. The Wald-test of the hypothesis that $\beta 1(0)$ is zero is 2.198 , which is statistically significant at the 1 percent level. Diebold and Rudebusch (1990), Sichel (1991) and Durland and McCurdy (1994) all conclude that duration dependence in postwar expansions is statistically insignificant. Our results contradict their findings. It is also interesting to note that the duration dependence we have uncovered is polar to the type considered in their work, which is motivated by the notion that, as an expansion ages, a contraction is increasingly imminent. Our results demonstrate that a new expansion is fragile and that a reversion to a contraction is most likely to occur when the expansion is in its infancy. According to the column 2 estimates, at the onset of an expansion the probability of remaining in this state is barely 0.80 . This probability, however, increases to 0.90 if the expansion survives for ten quarters and reaches 0.95 by the time the expansion is five years old.

Column 3 shows that, when the mean growth rates are allowed to depend quadratically upon duration, duration dependence in the transition probabilities is more pronounced. Column 3 differs from column 4 of Table 3 in only the duration dependence of the transition probabilities, but the difference between the two log-likelihoods exceeds 6 . Therefore, the null hypothesis of no duration dependence in the transition probabilities can easily be rejected. The estimated transition 
probabilities associated with a contraction exhibit even more pronounced duration dependence than in column 2 . When a contraction begins, the probability of remaining in a contractionary state is 0.89 . This is the magnitude one would expect to find for an expansion. This probability declines with the age of the contraction, but remains greater than 0.50 in the second quarter ${ }^{6}$.

In column 3, the mean growth rates exhibit the same pattern observed in Table 3. Output growth falls steadily over an expansion, while over a contraction the decline in output is slow in the beginning, but deteriorates as the contraction ages ${ }^{7}$. It is worth noting that this pattern bears a great deal of resemblance to the characterization of the business cycle given in Burns (1968), who writes that

The expansion, which ultimately carries aggregate activity to new heights, is typically most rapid in its early stages - the more so when it follows a severe contraction than when it follows a mild one. Although the rate of advance usually tapers off as the expansion proceeds, at times it reaccelerates as an expansion draws to a close without, however, regaining its initial speed. During contractions the rate of decline is usually fastest in the middle stages ${ }^{8}$.

The model in column 3 is less parsimonious. It is represented by 15 parameters, as compared to 11 in Durland and McCurdy (1994) and 9 in the benchmark Hamilton model. The additional parameters do, however, tremendously improve the maximized value of the loglikelihood; the maximized value for the Durland and McCurdy model is more than 12 points lower, while the maximized value of for the benchmark Hamilton model is more than 13 points lower. There are indeed nonlinear dynamics that are not captured by the constant transition

\footnotetext{
${ }^{6}$ It is interesting to note that Potter (1995) obtains a negative and quantitatively large AR(2) coefficient for the contractionary regime in his post-1945 SETAR. This estimate implies a tendency for output growth to recover two quarters after a negative impulse, which is broadly consistent with positive duration dependence in contractions. We also find positive duration dependence in the contraction transition probability. Our estimate indicates, however, that, conditional on remaining in a contraction, output growth tends to further decline instead of increasing.

${ }^{7}$ Kim and Nelson (1997) estimate Friedman's Plucking Model using postwar quarterly GDP and the unemployment rate. Their estimates imply the presence of three distinctive phases in business cycle dynamics: a recessionary phase, a high-growth recovery phase, and a normal phase. It is interesting to note that in our model the tendency for output growth to decline over an expansion is roughly equivalent to the transition from their model's highgrowth recovery phase to its normal phase.

${ }^{8}$ See Burns $(1968,230)$.
} 
probabilities model or the simple duration-dependent transition probabilities model. These dynamics are substantial from the view point of statistical inference. Furthermore, an important implication of Table 4 is that the detection of duration dependence in the transition probabilities does require a correct specification of the dynamics of the mean growth rates. The use of oversimplified dynamics with respect to the mean growth rates results in the failure to reject the null of no duration dependence.

\subsection{Matching the Postwar NBER Reference Cycle Chronology}

Figure 1 plots the smoothed estimates of the probability of being in a contraction, for each point in the sample from 1952:2 to $1995: 4$. That is, we estimate the probability of being in a contraction via the k-lag smoother given by equation (7), setting $\mathrm{k}$ equal to 4 . We compute these probabilities for the following three models: the benchmark Hamilton model, using the parameter values reported in Table 2; the model with quadratic duration dependence in the mean growth rates and constant transition probabilities, using the parameter values reported in column 4 of Table 3; and the model with quadratic duration dependence in the mean growth rates and duration dependence in the transition probabilities, using the parameter values reported in column 3 of Table 4. The results from these three models are plotted in Panels A, B and C, respectively. Recessionary episodes identified by the NBER are indicated by the shaded areas in the figures.

A remarkable achievement in Hamilton (1989) is his ability to generate an alternative business cycle chronology that nearly replicates the NBER reference cycle chronology. Panel A shows that this match deteriorates significantly with our updated and revised postwar data. If we classify as contractionary those quarters with an estimated probability of being in a contraction exceeding 0.50 , the identified contractionary episodes are generally too brief when compared to the NBER reference cycle chronology. For example, for the NBER-dated contraction occurring between 1969:4 and 1970:4, only 1970:4 is identified as a contraction by the smoother. More importantly, the smoother completely misses that contraction associated with the 1975 oil shock. Introducing duration dependence into the mean growth rates and the transition probabilities, as Panels B and C demonstrate, only marginally improves the match with the NBER reference cycle 
chronology. Both miss the NBER-dated contraction occurring in the early 1990s, which is mild by historical standards. The model with duration dependence in both the mean growth rate and the transition probabilities does, however, include more contractionary episodes than are identified by the NBER.

There is a simple explanation for this. Many of those contractions identified by the third model have durations of less than two quarters; in addition, the output declines are mild at the onset of the contraction. These periods of slow growth, therefore, might not be recognized by the NBER as business cycle episodes. To investigate this possibility, we compute the smoothed probabilities of being in a contraction, taking into account a maturity criterion that excludes from our chronology contractions with durations of two quarters or less. We estimate these probabilities using equation (8), setting $\mathrm{k}$ equal to 4 and $\lambda$ equal to 2 . Figure 2 plots these smoothed probabilities. The match with the NBER reference cycle chronology is indeed quite reasonable. It also appears that imposing an additional maturity criterion, under which a whole cycle must exceed 6 quarters, will further improve the match. Even better matches, however, can be found in a multivariate framework with higher frequency data. Kim and Yoo (1995) and Foertsch (1997), for example, match the NBER reference cycle chronology very well with a multivariate Markov switching model estimated using four monthly coincident indicators.

\subsection{Balke-Gordon Secular Quarterly Data}

Table 5 presents results for four cases of the general model. The first column is the benchmark Hamilton model. The second column is the Durland and McCurdy (1994) model. The third column is the model with duration-dependent transition probabilities and mean growth rates, with the latter of these being dependent linearly upon the duration of the current phase. The fourth column generalizes the third column to allow the duration of the current phase to affect the mean growth rates quadratically. There are two quantitative differences between these estimates and those based on the postwar data. First, the magnitude of the output fluctuations, judged either by the estimates of the mean growth rates across the phases or by the estimate of $\sigma$, is much larger in the secular data. Second, secular contractions are more persistent. The tendency in the 
postwar data to find a negative $\beta 0(1)$, or to find a low probability of remaining in a contraction, is absent in the secular data. This is not surprising given the presence in the sample of such prolonged, major contractions as the Great Depression.

The similarities between these estimates and those based upon the postwar data are, however, more striking. Table 6 compares the patterns of duration dependence across the two samples. These patterns are evaluated using the parameter values from those models with duration-dependent transition probabilities and mean growth rates, with the latter of these being dependent quadratically on the age of the current phase (column 3 of Table 4 and column 4 of Table 5). Panel A depicts the mean growth rates and probabilities of remaining in an expansion over a period of forty quarters. Panel B depicts analogous measures for a contraction over a period of 5 quarters. Note the striking similarities between the two patterns in Panel A. In both the secular and the postwar data, output grows at a high rate at the onset of an expansion and slows as the expansion ages; this pattern continues for approximately 30 quarters. Also, in both samples, the probability of reverting to a contraction is higher at the onset of the expansion. Panel B shows that in the secular data the mean growth rate rises after the first period of a contraction; however, unlike in the postwar data, it does not decline dramatically soon thereafter. There is also no tendency for the probability of exiting a contraction to increase.

It has been argued that a reason for the postwar stabilization of output is the lengthening of expansions (Diebold and Rudebusch 1992, Sichel 1991). Our results appear to contradict this argument. Table 6 indicates that the probability of reverting to a contraction is higher in the postwar data than in the secular data and that this remains the case until the expansion is almost ten years old. As a result, the implied average durations of postwar and secular expansions, according to Table 6, are 8.50 and 26.54 quarters, respectively. Our implied average duration for postwar expansions falls short of the average duration for the same reported by the NBER, which is around 17 quarters. Much of this shortfall can be attributed to the fact that temporary slowdowns in output growth may not be recognized by the NBER as contractions. If we follow a 'maturity criterion', labeling contractions with durations of 2 quarters or less as expansions, the implied average durations are 17.45 and 48.50 quarters, respectively, for postwar and secular 
expansions. Imposing a 'maturity criterion' does not alter the conclusion that expansions are actually shorter in the postwar data than in the secular data.

The differences between our results and those reported by Diebold and Rudebusch (1992) and Sichel (1991) arise from the use of different business cycle dating algorithms. They use the NBER reference cycle peak and trough dates to measure durations, while we use a statistical model to extract the business cycle as an unobserved component of the growth rate of output. Our approach applies a single dating algorithm to both the postwar and the Balke-Gordon secular data. In this sense, our results are consistent with Watson (1994), who argues that the apparent postwar duration stabilization of expansions is an artifact of inconsistent dating methods used by the NBER over time. The postwar stabilization of output, according to Table 6 , is the result of the reduced differences in the mean growth rates across expansions and contractions as well as the reduced persistence of contractions.

\subsection{Dependence on the Duration of the Previous Phase}

We now consider the possibility that the duration of the current phase depends upon the duration of the previous phase of the cycle. We examine this issue with the most general of the models estimated thus far, those presented in column 3 of Table 4 for the postwar data and in column 4 of Table 5 for the Balke-Gordon secular data. We augment the model with two free parameters, $\beta 2(0)$ and $\beta 2(1)$, so that there are now 17 estimable parameters. The results are reported in Table 7.

These results can be summarized briefly. First, $\beta 2(1)$ is positive over both the secular and the postwar samples. It is significant at the 2 percent level in the secular data, but not significant at the 10 percent level in the postwar data ${ }^{9}$. Second, $\beta 2(0)$ is positive in the secular data, negative in the postwar data, and statistically insignificant in both samples. Third, the estimated mean growth rates are essentially unchanged by the addition of the two parameters; however, the

\footnotetext{
${ }^{9}$ This lack of significance in the postwar data appears to be the result of the small sample size. The estimate based upon the sample starting in 1947:2 yields a t-statistic of -1.2, which is close to significance at the 10 percent level.
} 
addition of this second type of duration dependence does change the estimated relationship between the transition probability and the age of the contraction in the secular data. The new estimates suggest a statistically significant increase in the probability of exiting a contractionary state as the contraction ages. Consider a contraction following an expansion of 15 quarters. The probability of exiting the contraction is 0.033 in the first quarter, but 0.339 after one year, suggesting that both postwar and secular contractions exhibit positive duration dependence. With the exception of this finding, the comparison between the postwar and secular data in Table 6 remains valid.

The estimate of $\beta 2(1)$ implies that the longer the previous expansion, the more persistent is the current contraction. This result contradicts Neftci (1986), Sichel (1991) and Diebold (1993), who find that longer expansions tend to be followed by shorter contractions. The effect is quantitatively small in the postwar data. The expected duration of a contraction is 2.97 quarters if the duration of the previous expansion is 10 quarters. If the duration of the previous expansion is instead 30 quarters, this expected duration increases to 3.83 quarters. The effect is quantitatively large in the secular data. The expected duration of a contraction is 2.67 quarters if the duration of the previous expansion is 10 quarters. If the duration of the previous expansion is 30 quarters, this expected duration is 9.47 quarters.

The estimate of $\beta 2(0)$ implies that longer contractions are followed by dramatically shorter expansions in the postwar period. A contraction with a duration of 2 quarters tends to be followed by an expansion with a duration of 17.42 quarters; however, a contraction with a duration of 3 quarters tends to be followed by an expansion whose duration is only 6.82 quarters. This effect seems too large to be plausible and, in any case, is not precisely estimated. In the secular data, the estimate of $\beta 2(0)$ implies that longer contractions are typically followed by longer expansions. This effect is, however, quantitatively negligible. The estimate implies that a contraction lasting 2 quarters is expected to be followed by an expansion lasting 25.26 quarters; a contraction lasting 3 quarters is expected to be followed by an expansion lasting 26.17 quarters. This effect is also statistically insignificant. Overall, we do not find that the duration of the previous contraction has a significant effect on the duration of the subsequent expansion. 
We now use the estimated transition probabilities to derive the unconditional probability distributions for the length of a whole-cycle. Figure 3A plots these distributions for peak-to-peak and trough-to-trough whole-cycles, computed using estimates from the secular data. Figure 3B plots the same, computed using estimates from the postwar data. In each figure, we also include for comparison a plot of the distribution for the benchmark Hamilton model in which all forms of duration dependence are absent. The Hamilton model is calibrated to have the same expected phase durations (for both expansions and contractions) as the estimated general model.

Figure $3 \mathrm{~A}$ shows that, when compared to the benchmark of duration independence, whole-cycle are more frequent around shorter durations and less frequent around longer durations in the secular data. There is no evidence, therefore, of a clustering of the whole-cycle around the seven-to-ten year durations discussed in Diebold and Rudebusch (1990), among others. This result mainly reflects the interplay of the estimated positive duration dependence in contractions and negative duration dependence in expansions. The tendency of contractions to end in a few quarters, combined with the tendency of expansions to terminate prematurely, causes a significant presence of the whole-cycle around short durations. Figure 3B reveals similar patterns in postwar whole-cycles. Because the estimated positive duration dependence in contractions and negative duration dependence in expansions are stronger. As a result, the tendency to find short wholecycles is more pronounced.

One reason for the significant presence of the whole-cycle around short durations is our classification of brief declines in output as contractions. These brief declines in output are unlikely to be recognized by the NBER as contractions. For purposes of comparison, we reconsider the length of the whole-cycle, this time imposing a 'maturity criterion' similar to that used by the NBER. Figure 4 depicts the distributions of the peak-to-peak and trough-to-trough whole-cycle lengths implied by the model estimated using the postwar data and computed under the condition that only contractions exceeding two quarters are recognized as such. The distribution implied by the Hamilton model calibrated to the estimated model is again included for comparison. The major effect of imposing a 'maturity criterion' is a shifting of the distributions to the right. Compared to 
the benchmark of duration independence, we still find more short and fewer long whole-cycles. Again, there is no evidence consistent with the clustering of the whole-cycle around seven-to-ten year durations.

Diebold and Rudebusch (1990) reject the hypothesis of no peak-to-peak and trough-totrough periodicities in the NBER reference cycle turning points. While we also find evidence of a departure from the benchmark of duration independence, the departure we find does not point to the seven-to-ten year whole-cycle motivating their hypothesis testing. In order for business cycles to cluster around seven-to-ten year durations, positive but small duration dependence must be present in the transition probabilities associated with expansions. We, in contrast, find negative duration dependence in expansions. This negative duration dependence tends to produce cycles that are either very short or very long.

\section{Concluding Remarks}

We have used a regime-switching model of real GNP growth to examine the duration dependence of business cycles. The model is an extended version of Hamilton (1989) and Durland and McCurdy (1994), and we estimate using both the postwar NIPA data and the secular data constructed by Balke and Gordon (1986).

Three empirical findings are worth emphasizing. First, we uncover not only a decline in the growth rate of output over the course of an expansion, but also a simultaneous reduction in the propensity to revert to a contraction. This pattern is robust to sample period as well as to model specification. Second, we find that the probability of exiting a contractionary state increases as the contraction ages. Third, we find that the length of an expansion has a positive effect on the duration of the subsequent contraction. This effect is quantitatively large and statistically significant in the Balke-Gordon secular data. Taken together, the duration dependence that we have estimated does not support the clustering of the whole-cycle around the seven-to-ten year 
durations discussed in the literature. This is the case even when we impose a 'maturity criterion' in measuring our whole-cycles.

Our findings suggest the existence of complicated nonlinear dynamics in output growth. As income and output are closely related, similar dynamics are most likely to be found in income as well. The standard forward-looking consumption theory implies that the savings rate is the present value of expected future declines in income growth. If the probability of an expansion ending is decreasing in its age, the savings rate should be higher after a business cycle trough than near a business cycle peak. In an exchange economy, the nonlinear dynamics in endowments imply nonlinear dynamics in asset prices and returns. If endowment growth has slowed and the risk of falling into a contraction has fallen substantially over the course of an expansion, at the peak of a cycle there may be little uncertainty with regard to endowment growth. This may potentially explain the stylized fact that the equity premium tends to be higher near a business cycle trough than at a business cycle peak. Future research might exploit the restrictions implied by these nonlinear dynamics to implement sharper tests of economic models. 


\section{References}

1. Balke, Nathan and Robert J. Gordon. "Appendix B: Historical Data" in The American Business Cycle: Continuity and Change, Robert Gordon (ed.), National Bureau of Economic Research, University of Chicago Press, 1986, 789-809.

2. Bureau of Economic Analysis, Department of Commerce. "Preview of the Comprehensive Revision of the National Income and Product Accounts: BEA's New Featured Measures of Output and Prices," Survey of Current Business, July 1995, 3138.

3. Bureau of Economic Analysis, Department of Commerce. "Table 2A-Real Gross Domestic Product." Survey of Current Business, May 1997, 15-17.

4. Burns, Arthur F., "Business Cycles." in International Encyclopedia of the Social Sciences, Volume II, David L. Sills (ed.), (The Macmillan Company \& The Free Press, 1968), 226-249. Reprinted in The Business Cycle in a Changing World (New York: NBER, 1969), Arthur Burns (ed.), 3-51.

5. Diebold, F. X. and G. D. Rudebusch. "A Non-parametric Investigation of Duration Dependence in the American Business Cycle." Journal of Political Economy, June 1990, 98, 596-616.

6. Diebold, F. X. and G. D. Rudebusch. "Have Postwar Fluctuations been Stabilized?" American Economic Review, September 1992, 993-1005.

7. Diebold, F. X.. " Are Long Expansions Followed by Short Contractions?" Business Review, Federal Reserve Bank of Philadelphia, July-August 1993, 3-11.

8. Durland, J. Michael and Thomas H. McCurdy. "Duration-Dependent Transitions in a Markov Model of U. S. GNP Growth", Journal of Business \& Economic Statistics, July 1994, 279-288.

9. Foertsch, Tracy. "Business Cycle Measurement Using a Dynamic Factor Model with Duration Dependent Transitions." unpublished dissertation, The Ohio State University, Department of Economics, 1997.

10. Hamilton, James D. "A New Approach to the Economic Analysis of Non-stationary Time Series and the Business Cycle." Econometrica, 1989, 57,357-384.

11. Kim, Chang-Jin. "Dynamic Linear Model with Markov Switching." Journal of Econometrics, January-February, 1994, 1-22. 
12. Kim, Chang-Jin, and Charles R. Nelson, "Friedman's Plucking Model of Business Fluctuations: Tests and Estimates of Permanent and Transitory Components," Unpublished manuscript, Department of Economics, University of Washington, February, 1997.

13. Kim, Myung-Jig and Ji-Sung Yoo. "New Index of Coincident Indicators: A Multivariate Markov Switching Factor Model Approach." Journal of Monetary Economics, 1995, 607-630.

14. Lam, Pok-sang. "The Hamilton Model With a General Autoregressive Component: Estimation and Comparison with Other Economic Time Series." Journal of Monetary Economics, 26, December 1990, 409-432.

15. McCulloch, Huston J. "The Monte Carlo Cycle In Business Activity." Economic Inquiry, September 1975, 303-321.

16. Neftci, Salih N. "Optimal Prediction of Cyclical Downturns." Journal of Economic Dynamics \& Control 4, August 1982, 225-41.

17. Neftci, Salih N. "Is there a Cyclical Time Unit?" Carnegie-Rochester Conference Series on Public Policy, Spring 1986, 11-48.

18. Potter, Simon M., "A Nonlinear Approach to US GNP." Journal of Applied Econometrics, Volume 10, 1995, 109-125.

19. Sichel, Daniel E. "Business Cycle Duration Dependence: A Parametric Approach." Review of Economics and Statistics, May 1991, 254-260.

20. Watson, Mark W. "Business Cycles Durations and Postwar Stabilization of the U.S. Economy." American Economic Review, March 1994, 24-46. 
Table 1: The Model and Its Parameters

A. The Model

$$
\begin{aligned}
& y_{t}=\alpha 0\left(S_{t}\right)+\alpha 1\left(S_{t}\right)\left(D D_{t}-1\right)+\alpha 2\left(S_{t}\right)\left(D D_{t}-1\right)^{2}+z_{t} \\
& \left(1-\phi 1 L-\phi 2 L^{2}-\ldots-\phi k L^{k}\right) z_{t}=\varepsilon_{t}, \varepsilon_{t} \sim N . i . i . d .\left(0, \sigma^{2}\right) \\
& S_{t} \in\{0,1\} \\
& \operatorname{Pr}\left[S_{t+1}=s / S_{t}=s, D_{t}, D L_{t}\right]=\frac{\exp \left[\beta 0(s)+\beta 1(s)\left(D D_{t}-1\right)+\beta 2(s)\left(D D L_{t}-1\right)\right]}{1+\exp \left[\beta 0(s)+\beta 1(s)\left(D D_{t}-1\right)+\beta 2(s)\left(D D L_{t}-1\right)\right]},
\end{aligned}
$$

\begin{tabular}{|c|c|c|}
\hline \multirow[t]{6}{*}{$\begin{array}{l}\text { Mean Growth } \\
\text { Rate }\end{array}$} & $\alpha 0(0)$ & Mean growth rate during the first period of an expansion. \\
\hline & $\alpha 1(0)$ & $\begin{array}{l}\text { Linear coefficient in the relationship between the mean growth rate and } \\
\text { the age of the expansion. }\end{array}$ \\
\hline & $\alpha 2(0)$ & $\begin{array}{l}\text { Quadratic coefficient in the relationship between the mean growth rate } \\
\text { and the age of the expansion. }\end{array}$ \\
\hline & $\alpha 0(1)$ & Mean growth rate during the first period of a contraction \\
\hline & $\alpha 1(1)$ & $\begin{array}{l}\text { Linear coefficient in the relationship between the mean growth rate and } \\
\text { the age of the contraction. }\end{array}$ \\
\hline & $\alpha 2(1)$ & $\begin{array}{l}\text { Quadratic coefficient in the relationship between the mean growth rate } \\
\text { and the age of the contraction. }\end{array}$ \\
\hline \multirow[t]{6}{*}{$\begin{array}{c}\text { Transition } \\
\text { Probabilities }\end{array}$} & $\beta 0(0)$ & Constant coefficient in the probability that an expansion survives. \\
\hline & $\beta 1(0)$ & $\begin{array}{l}\text { Effect of the age of the current expansion on the probability that an } \\
\text { expansion survives. } \beta 1(0)<0 \equiv \text { positive duration dependence; } \beta 1(0)> \\
0 \equiv \text { negative duration dependence. }\end{array}$ \\
\hline & $\beta 2(0)$ & $\begin{array}{l}\text { Effect of the length of the last contraction on the probability that an } \\
\text { expansion survives. } \beta 2(0)>0 \Rightarrow \text { Probability of an expansion continuing } \\
\text { increases with the length of the previous contraction. }\end{array}$ \\
\hline & $\beta 0(1)$ & Constant coefficient in the probability that a contraction survives. \\
\hline & $\beta 1(1)$ & $\begin{array}{l}\text { Effect of the age of the current contraction on the probability that a } \\
\text { contraction survives. } \beta 1(1)<0 \equiv \text { positive duration dependence; } \beta 1(1)> \\
0 \equiv \text { negative duration dependence. }\end{array}$ \\
\hline & $\beta 2(1)$ & $\begin{array}{l}\text { Effect of the length of the last expansion on the probability that a } \\
\text { contraction survives. } \beta 2(0)>0 \Rightarrow \text { Probability of a contraction } \\
\text { continuing increases with the length of the previous expansion. }\end{array}$ \\
\hline \multirow{2}{*}{$\begin{array}{l}\text { Autoregressive } \\
\text { Process }\end{array}$} & $\phi \mathrm{i}$ & i-th autoregressive parameter. \\
\hline & $\sigma$ & Standard deviation of an innovation in the autoregressive process. \\
\hline
\end{tabular}

where $D D_{t}=\operatorname{Min}\left(D_{t}, d m\right), D D L_{t}=\operatorname{Min}\left(D L_{t}, d m\right), \mathrm{s}=0,1$,

$\mathrm{D}$ is the age of the current run of states, and DL is the duration of the last run of states.

\section{B. The Parameters}


Table 2: Maximum-Likelihood Estimates of the Benchmark Hamilton Model

\begin{tabular}{|c|c|}
\hline Parameters & Estimates \\
\hline$\alpha 0(0)$ & 0.852 \\
& $(0.093)$ \\
\hline$\alpha 0(1)$ & -1.500 \\
& $(0.453)$ \\
\hline$\beta 0(0)$ & 3.343 \\
& $(0.594)$ \\
\hline$\beta 0(1)$ & -1.338 \\
& $(1.534)$ \\
\hline$\sigma$ & 0.810 \\
& $(0.054)$ \\
\hline$\phi 1$ & 0.388 \\
& $(0.084)$ \\
\hline$\phi 2$ & 0.097 \\
& $(0.102)$ \\
\hline$\phi 3$ & -0.106 \\
& $(0.099)$ \\
\hline$\phi 4$ & -0.127 \\
& $(0.083)$ \\
\hline \multicolumn{2}{|c|}{} \\
\hline Log-likelihood & -238.231 \\
\hline Note: The model is estimated using 100 times the \\
log-difference of quarterly real GNP, 1952:2 \\
to 1996:4. Standard errors are in parenthesis. \\
See Table 1 for a description of the model \\
and for a definition of its parameters. \\
\hline
\end{tabular}




\begin{tabular}{|c|c|c|c|c|}
\hline \multicolumn{5}{|c|}{$\begin{array}{c}\text { Table 3: Maximum-Likelihood } \\
\text { Mean Growth Rates }\end{array}$} \\
\hline Parameters & \multicolumn{4}{|c|}{ Estimates } \\
\hline$\alpha 0(0)$ & $\begin{array}{c}1.3464 \\
(0.1294) \\
\end{array}$ & $\begin{array}{c}0.8537 \\
(0.0889) \\
\end{array}$ & $\begin{array}{c}1.3544 \\
(0.1266) \\
\end{array}$ & $\begin{array}{c}1.5662 \\
(0.1724)\end{array}$ \\
\hline$\alpha 1(0)$ & $\begin{array}{c}-0.0214 \\
(0.0051)\end{array}$ & - & $\begin{array}{c}-0.0216 \\
(0.0050)\end{array}$ & $\begin{array}{c}-0.0694 \\
(0.0293)\end{array}$ \\
\hline$\alpha 2(0)$ & - & - & - & $\begin{array}{c}0.0011 \\
(0.0007)\end{array}$ \\
\hline$\alpha 0(1)$ & $\begin{array}{l}-1.2222 \\
(0.2621)\end{array}$ & $\begin{array}{l}-1.3169 \\
(0.5032)\end{array}$ & $\begin{array}{l}-1.2791 \\
(0.3120)\end{array}$ & $\begin{array}{l}-0.8123 \\
(0.2816)\end{array}$ \\
\hline$\alpha 1(1)$ & - & $\begin{array}{l}-0.8534 \\
(1.0684)\end{array}$ & $\begin{array}{c}0.0766 \\
(0.2411)\end{array}$ & $\begin{array}{c}1.4225 \\
(0.4000)\end{array}$ \\
\hline$\alpha 2(1)$ & - & - & - & $\begin{array}{c}-0.6571 \\
(0.1485)\end{array}$ \\
\hline$\beta 0(0)$ & $\begin{array}{r}3.1290 \\
(0.4186)\end{array}$ & $\begin{array}{c}3.3158 \\
(0.5825)\end{array}$ & $\begin{array}{c}3.1352 \\
(0.4132)\end{array}$ & $\begin{array}{c}2.7266 \\
(0.4260)\end{array}$ \\
\hline$\beta 0(1)$ & $\begin{array}{l}-0.0119 \\
(0.6516)\end{array}$ & $\begin{array}{l}-1.4137 \\
(1.1667)\end{array}$ & $\begin{array}{c}0.0210 \\
(0.6364)\end{array}$ & $\begin{array}{c}0.2561 \\
(0.4571)\end{array}$ \\
\hline$\sigma$ & $\begin{array}{c}0.7366 \\
(0.0426)\end{array}$ & $\begin{array}{c}0.8090 \\
(0.0520)\end{array}$ & $\begin{array}{c}0.7349 \\
(0.0426)\end{array}$ & $\begin{array}{c}0.6873 \\
(0.0444)\end{array}$ \\
\hline$\phi 1$ & $\begin{array}{c}0.3270 \\
(0.0860)\end{array}$ & $\begin{array}{c}0.3880 \\
(0.0816)\end{array}$ & $\begin{array}{c}0.3259 \\
(0.0850)\end{array}$ & $\begin{array}{c}0.3591 \\
(0.0908)\end{array}$ \\
\hline$\phi 2$ & $\begin{array}{l}-0.0024 \\
(0.0973)\end{array}$ & $\begin{array}{c}0.0790 \\
(0.0963)\end{array}$ & $\begin{array}{c}-0.0066 \\
(0.0973)\end{array}$ & $\begin{array}{c}0.1816 \\
(0.1160)\end{array}$ \\
\hline$\phi 3$ & $\begin{array}{l}-0.1446 \\
(0.1022)\end{array}$ & $\begin{array}{l}-0.0924 \\
(0.0951)\end{array}$ & $\begin{array}{c}-0.1553 \\
(0.1053)\end{array}$ & $\begin{array}{c}-0.2053 \\
(0.0917)\end{array}$ \\
\hline$\phi 4$ & $\begin{array}{l}-0.1325 \\
(0.1003)\end{array}$ & $\begin{array}{l}-0.1111 \\
(0.0861)\end{array}$ & $\begin{array}{c}-0.1244 \\
(0.0998)\end{array}$ & $\begin{array}{l}-0.1585 \\
(0.0884)\end{array}$ \\
\hline Log-likelihood & -233.400 & -238.033 & -233.351 & -230.955 \\
\hline Note: The model & $\begin{array}{l}\text { stimated us } \\
\text { 4. Standar } \\
\mathrm{d} \text { for a def }\end{array}$ & $\begin{array}{l}\text { times th } \\
\text { are in pe } \\
\text { f its para }\end{array}$ & ifference $c$ & $\begin{array}{l}\text { rly real } \mathrm{Gl} \\
\text { a descript }\end{array}$ \\
\hline
\end{tabular}




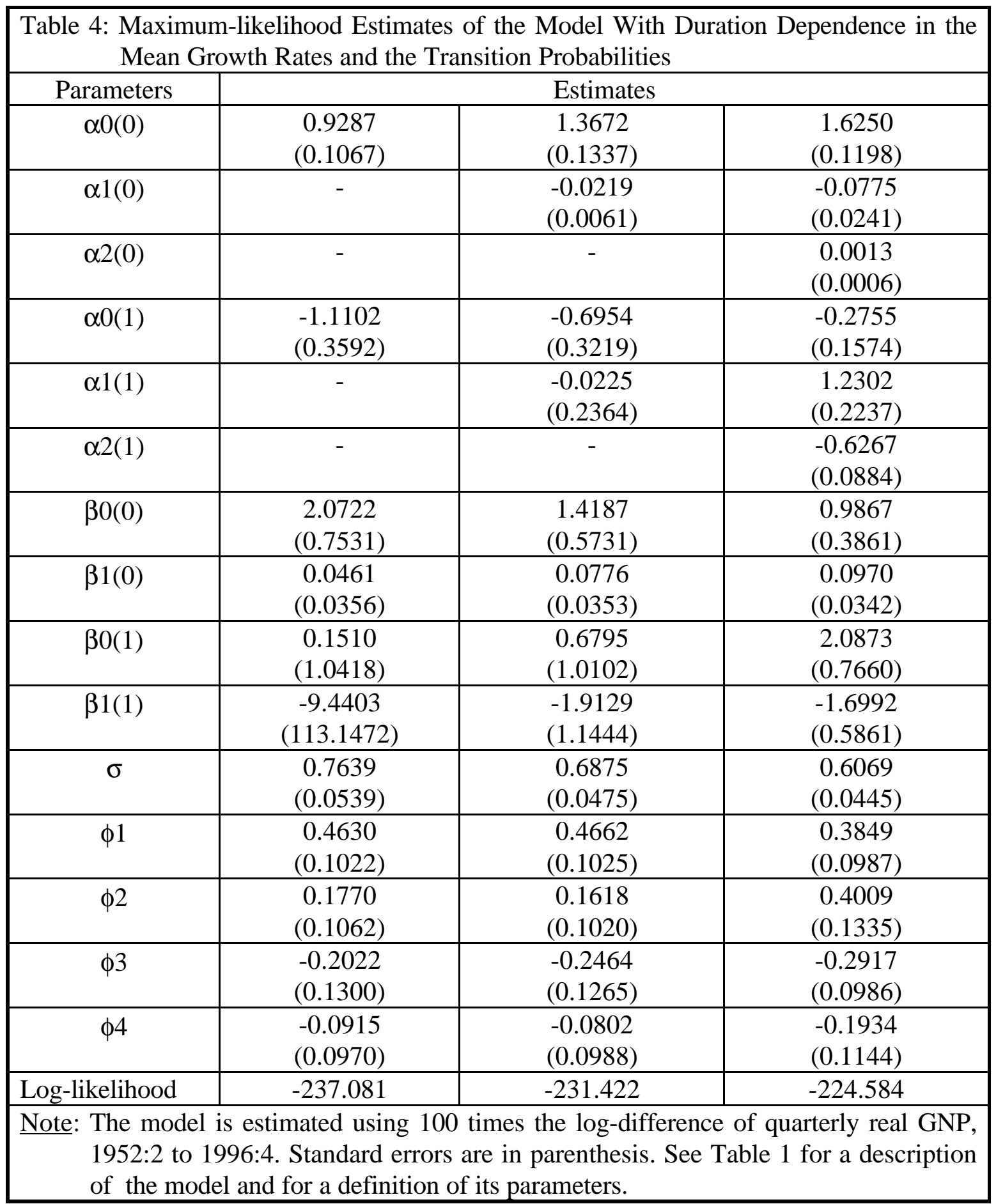




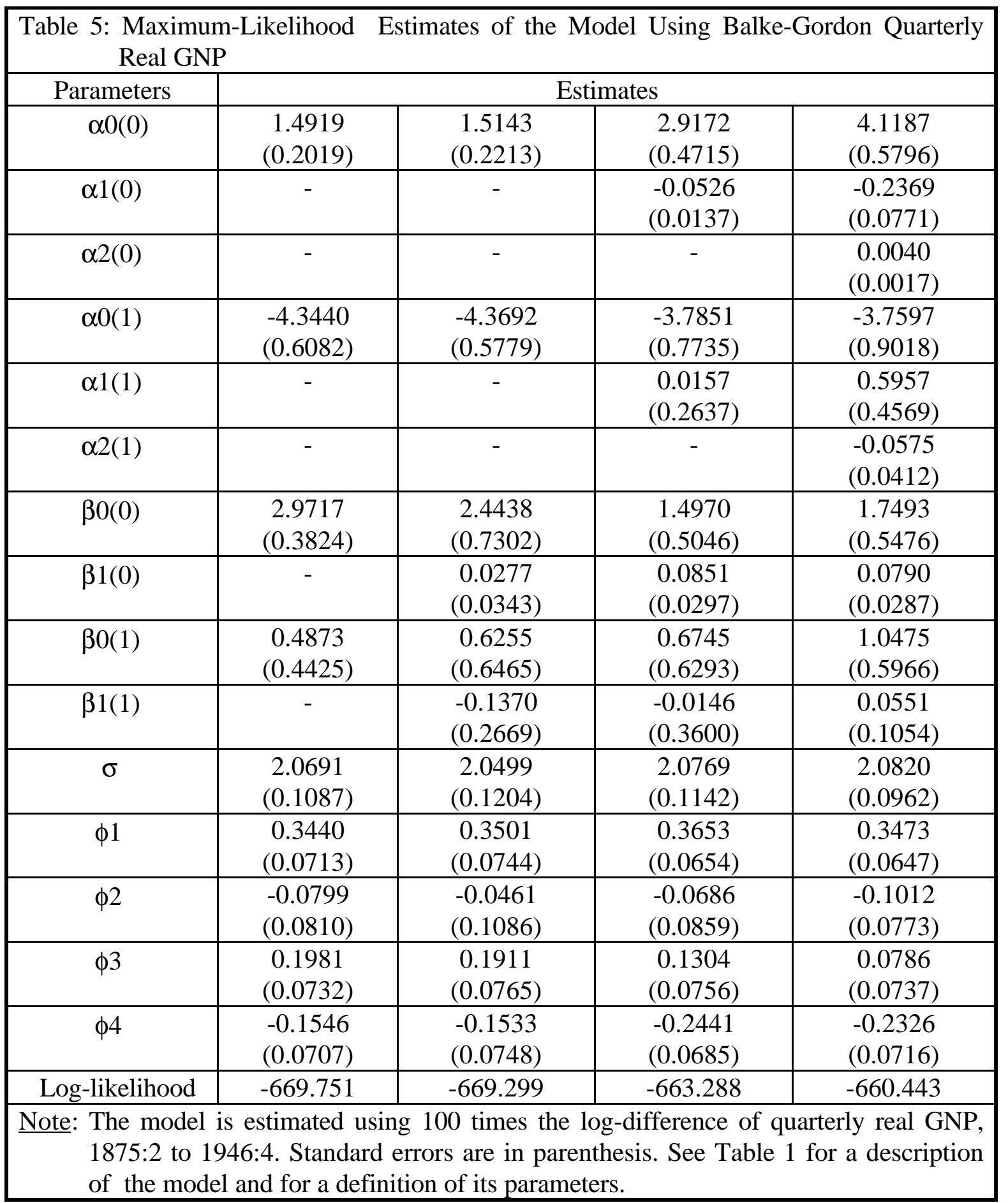




\begin{tabular}{|c|c|c|c|c|}
\hline \multicolumn{5}{|l|}{ A: Expansions } \\
\hline & \multicolumn{2}{|c|}{ Postwar } & \multicolumn{2}{|c|}{ Balke-Gordon } \\
\hline Duration & $\begin{array}{l}\text { Mean Growth } \\
\text { Rates }\end{array}$ & Probabilities & $\begin{array}{l}\text { Mean Growth } \\
\text { Rates }\end{array}$ & Probabilities \\
\hline 1 & 1.625 & 0.728 & 4.119 & 0.852 \\
\hline 3 & 1.475 & 0.765 & 3.661 & 0.871 \\
\hline 5 & 1.336 & 0.798 & 3.235 & 0.887 \\
\hline 7 & 1.206 & 0.828 & 2.841 & 0.902 \\
\hline 9 & 1.087 & 0.854 & 2.479 & 0.915 \\
\hline 11 & 0.979 & 0.876 & 2.149 & 0.927 \\
\hline 13 & 0.881 & 0.896 & 1.850 & 0.937 \\
\hline 15 & 0.793 & 0.913 & 1.584 & 0.946 \\
\hline 17 & 0.716 & 0.927 & 1.349 & 0.953 \\
\hline 19 & 0.649 & 0.939 & 1.147 & 0.960 \\
\hline 21 & 0.592 & 0.949 & 0.976 & 0.965 \\
\hline 23 & 0.546 & 0.958 & 0.837 & 0.970 \\
\hline 25 & 0.510 & 0.965 & 0.731 & 0.975 \\
\hline 27 & 0.484 & 0.971 & 0.656 & 0.978 \\
\hline 29 & 0.469 & 0.976 & 0.613 & 0.981 \\
\hline 31 & 0.464 & 0.980 & 0.601 & 0.984 \\
\hline 33 & 0.469 & 0.984 & 0.622 & 0.986 \\
\hline 35 & 0.485 & 0.986 & 0.675 & 0.988 \\
\hline 37 & 0.511 & 0.989 & 0.759 & 0.990 \\
\hline 39 & 0.548 & 0.991 & 0.876 & 0.991 \\
\hline \multicolumn{5}{|c|}{ B: Contractions } \\
\hline & \multicolumn{2}{|c|}{ Postwar } & \multicolumn{2}{|c|}{ Balke-Gordon } \\
\hline Duration & $\begin{array}{c}\text { Mean Growth } \\
\text { Rates }\end{array}$ & Probabilities & $\begin{array}{l}\text { Mean Growth } \\
\text { Rates }\end{array}$ & Probabilities \\
\hline 1 & -0.275 & 0.890 & -3.760 & 0.740 \\
\hline 2 & 0.328 & 0.596 & -3.221 & 0.751 \\
\hline 3 & -0.322 & 0.212 & -2.798 & 0.761 \\
\hline 4 & -2.225 & 0.047 & -2.490 & 0.771 \\
\hline 5 & -5.382 & 0.009 & -2.296 & 0.780 \\
\hline
\end{tabular}




\begin{tabular}{|c|c|c|}
\hline Parameters & \multicolumn{2}{|c|}{ Estimates } \\
\hline & Postwar & Balke-Gordon \\
\hline$\alpha 0(0)$ & $\begin{array}{c}1.6625 \\
(0.1368) \\
\end{array}$ & $\begin{array}{c}4.2752 \\
(0.5264) \\
\end{array}$ \\
\hline$\alpha 1(0)$ & $\begin{array}{l}-0.0848 \\
(0.0257)\end{array}$ & $\begin{array}{l}-0.2509 \\
(0.0730)\end{array}$ \\
\hline$\alpha 2(0)$ & $\begin{array}{c}0.0015 \\
(0.0006)\end{array}$ & $\begin{array}{c}0.0043 \\
(0.0016)\end{array}$ \\
\hline$\alpha 0(1)$ & $\begin{array}{l}-0.3168 \\
(0.1998)\end{array}$ & $\begin{array}{l}3.8761 \\
(0.7956)\end{array}$ \\
\hline$\alpha 1(1)$ & $\begin{array}{c}1.3412 \\
(0.2732)\end{array}$ & $\begin{array}{c}0.7238 \\
(0.3981)\end{array}$ \\
\hline$\alpha 2(1)$ & $\begin{array}{l}-0.6522 \\
(0.1024) \\
\end{array}$ & $\begin{array}{l}-0.0689 \\
(0.0357) \\
\end{array}$ \\
\hline$\beta 0(0)$ & $\begin{array}{c}2.1997 \\
(1.2721)\end{array}$ & $\begin{array}{c}1.6637 \\
(0.6265)\end{array}$ \\
\hline$\beta 1(0)$ & $\begin{array}{c}0.0700 \\
(0.0425)\end{array}$ & $\begin{array}{c}0.0815 \\
(0.0307)\end{array}$ \\
\hline$\beta 2(0)$ & $\begin{array}{l}-0.5005 \\
(0.5569)\end{array}$ & $\begin{array}{c}0.0170 \\
(0.1606)\end{array}$ \\
\hline$\beta 0(1)$ & $\begin{array}{c}2.8415 \\
(1.2190)\end{array}$ & $\begin{array}{l}-0.7960 \\
(0.8836)\end{array}$ \\
\hline$\beta 1(1)$ & $\begin{array}{l}-2.3739 \\
(0.9318)\end{array}$ & $\begin{array}{l}-0.5359 \\
(0.3056)\end{array}$ \\
\hline$\beta 2(1)$ & $\begin{array}{c}0.1022 \\
(0.1034)\end{array}$ & $\begin{array}{c}0.2195 \\
(0.0982) \\
\end{array}$ \\
\hline$\sigma$ & $\begin{array}{c}0.6429 \\
(0.0398)\end{array}$ & $\begin{array}{c}2.0861 \\
(0.0940)\end{array}$ \\
\hline$\phi 1$ & $\begin{array}{c}0.3690 \\
(0.0942)\end{array}$ & $\begin{array}{c}0.3459 \\
(0.0657)\end{array}$ \\
\hline$\phi 2$ & $\begin{array}{c}0.2834 \\
(0.1165)\end{array}$ & $\begin{array}{l}-0.0808 \\
(0.0734)\end{array}$ \\
\hline$\phi 3$ & $\begin{array}{l}-0.2037 \\
(0.1018)\end{array}$ & $\begin{array}{c}0.0672 \\
(0.0677)\end{array}$ \\
\hline$\phi 4$ & $\begin{array}{l}-0.1612 \\
(0.0962)\end{array}$ & $\begin{array}{l}-0.2183 \\
(0.0633)\end{array}$ \\
\hline Log-likelihood & -223.845 & -654.730 \\
\hline $\begin{array}{r}\text { Note: The mode } \\
\text { extending } \\
1946: 4 \mathrm{fc} \\
\text { Table } 1 \mathrm{f} \\
\end{array}$ & $\begin{array}{l}\text { ing } 100 \mathrm{t} \\
1996: 4 \\
\text { rdon san } \\
\text { f the mo }\end{array}$ & $\begin{array}{l}\text { ice of quarterly real GNP, } \\
\text { nple and from } 1875: 2 \text { to } \\
\text { s are in parenthesis. See } \\
\text { ion of its parameters. }\end{array}$ \\
\hline
\end{tabular}


Figure 1A: Smoothed Probabilities from the Benchmark Hamilton Model

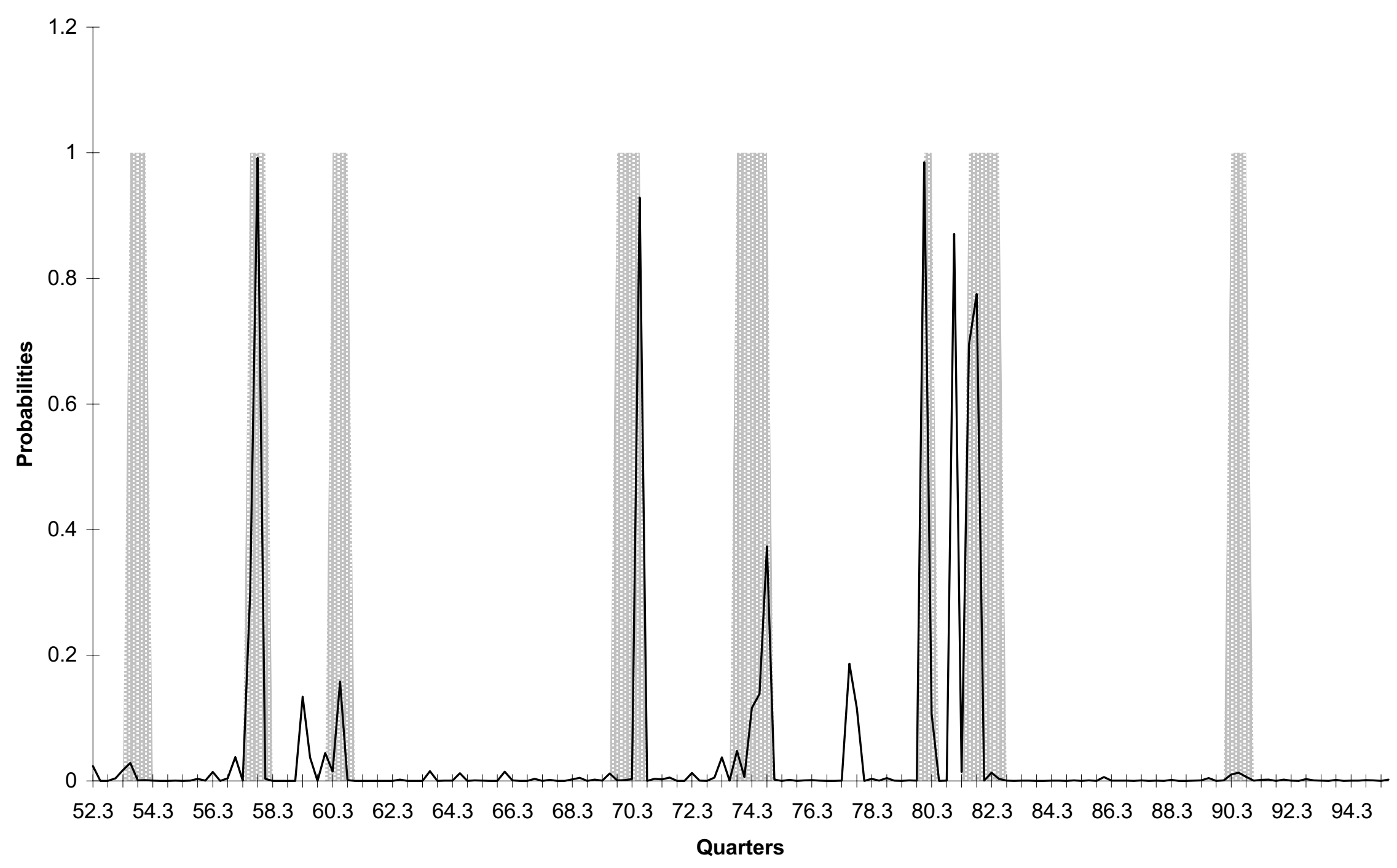


Figure 1B: Smoothed Probabilities from the Model with Duration Dependence in the Mean Growth Rates




Figure 1C: Smoothed Probabilities from the Model with Duration Dependence in the Mean Growth Rates and Transition Probabilities

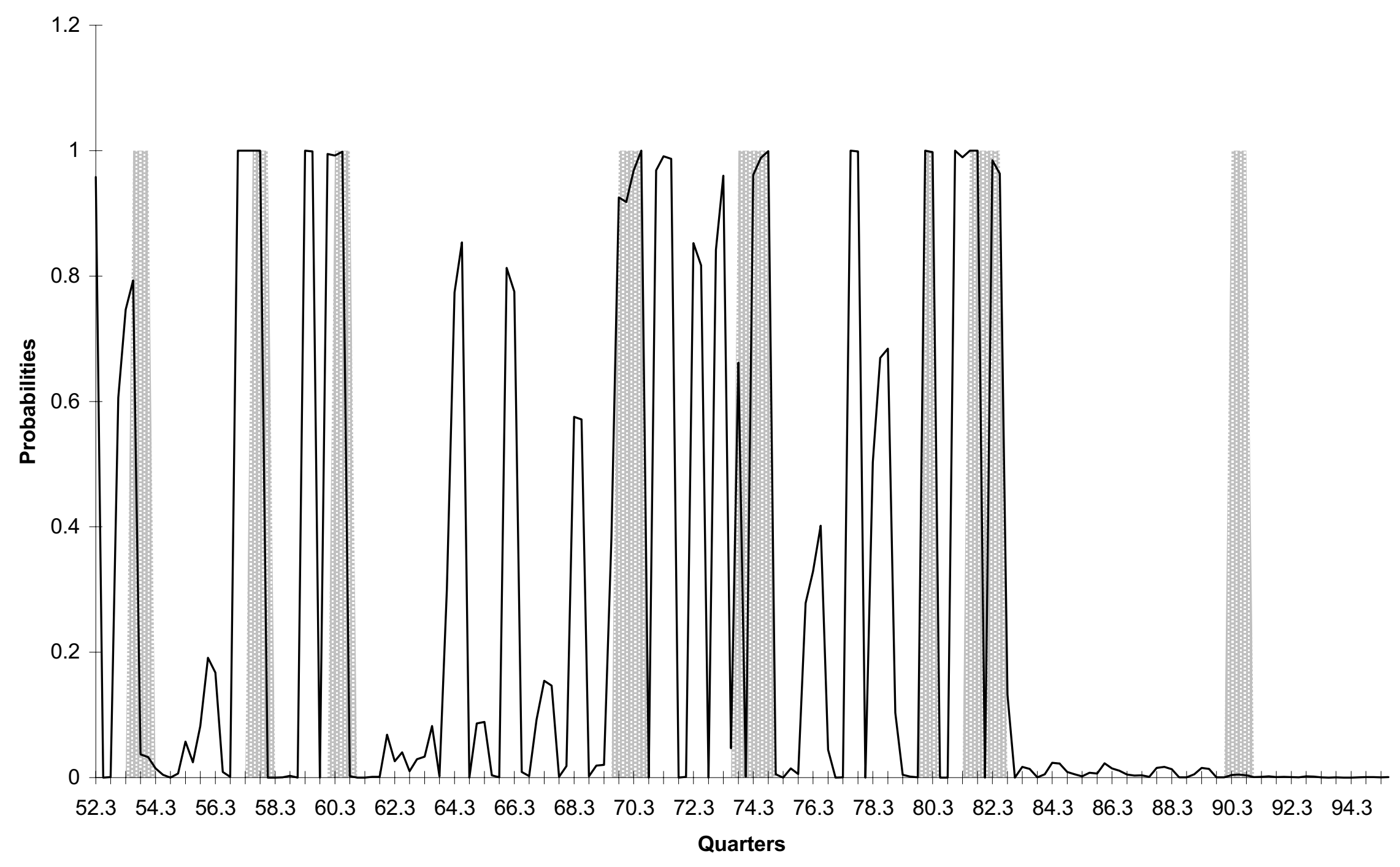


Figure 2: Smoothed Probabilities of Being in a Contraction After Imposing a Maturity Criterion

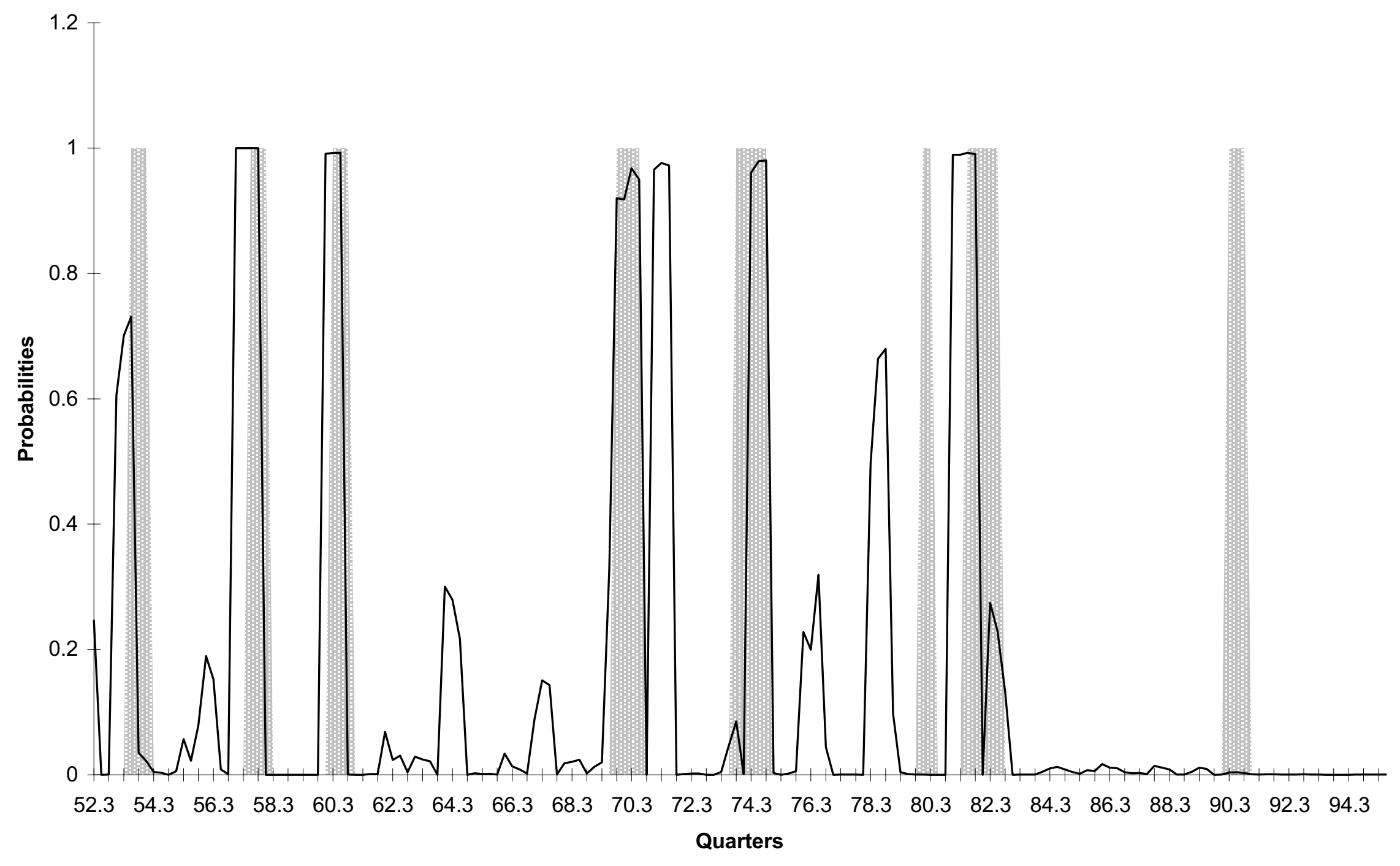


Figure 3A: Probability Distribution of the Length of a Whole-Cycle (Balke-Gordon Secular Data)

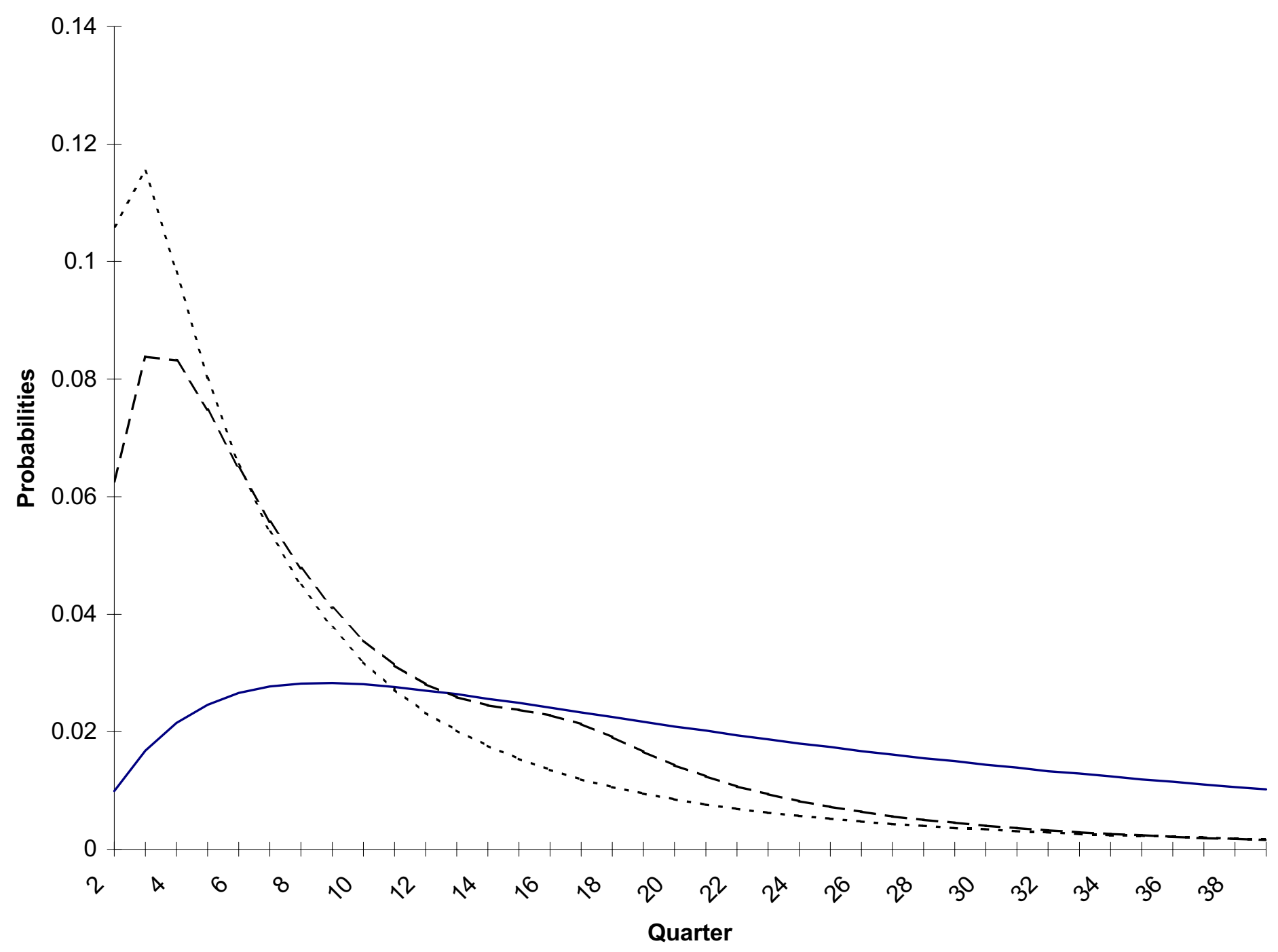


Figure 3B: Probability Distribution of the Length of a Whole-Cycle (Postwar Data)

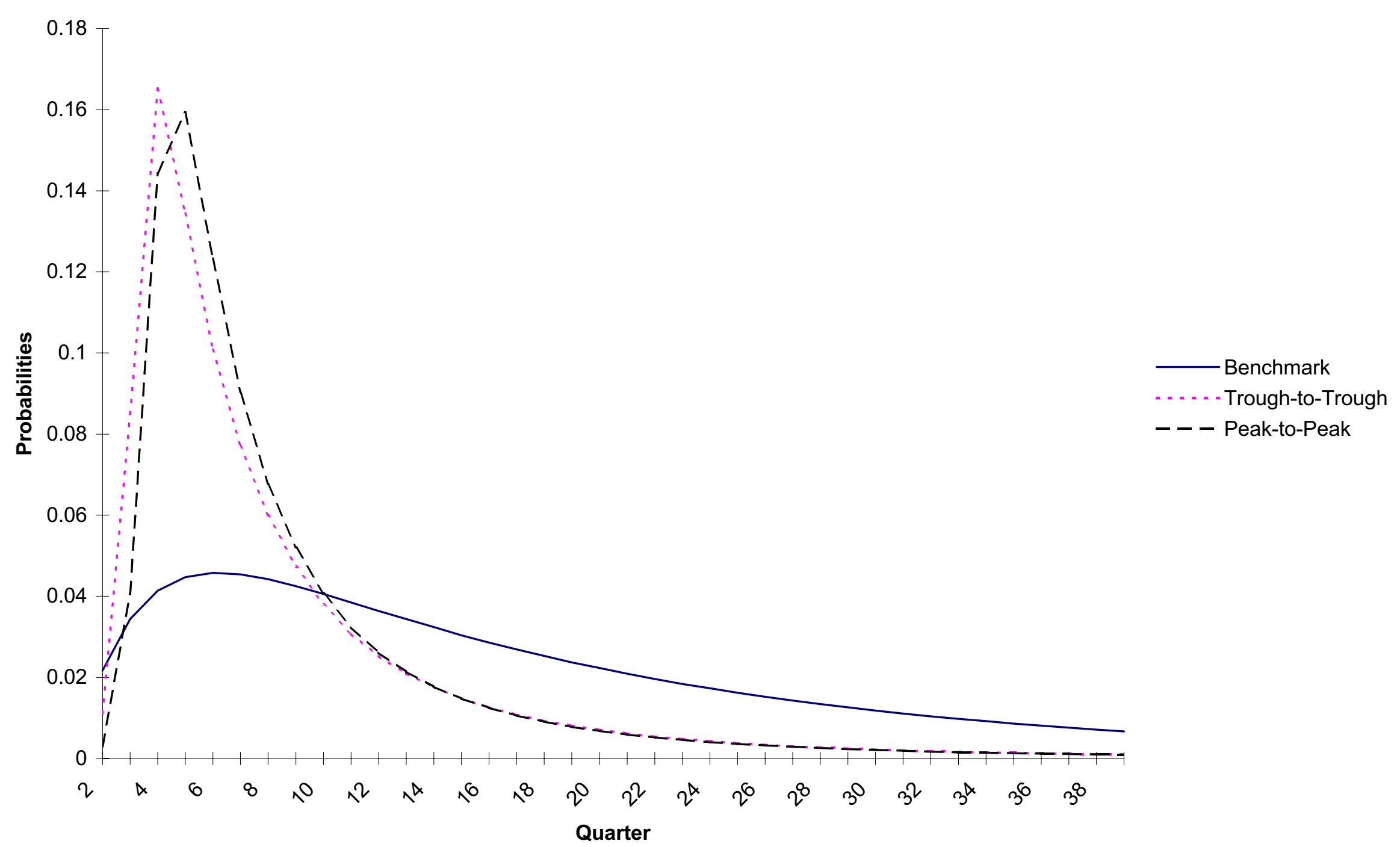


Figure 4: Probability Distribution of the Length of a Whole-Cycle After Imposing a Maturity Criterion (Postwar Data)

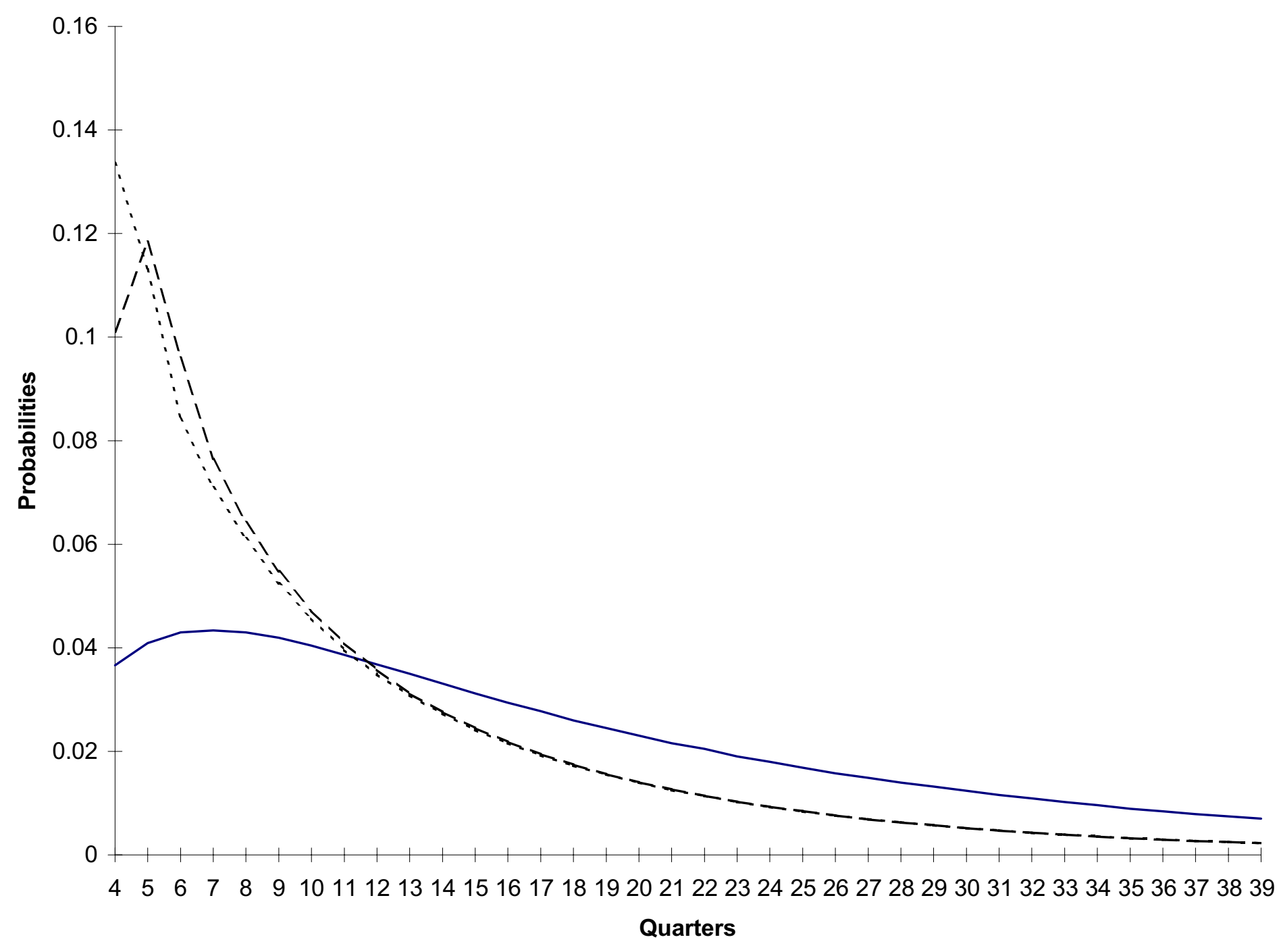

